\title{
WestVirginiaUniversity
}

THE RESEARCH REPOSITORY @ WVU

West Virginia Agricultural and Forestry Experiment

Davis College of Agriculture, Natural Resources

Station Bulletins

And Design

$1-1-1974$

\section{Stability and strength properties of wood columns}

Laszlo O. Keresztesy

Follow this and additional works at: https://researchrepository.wvu.edu/ wv_agricultural_and_forestry_experiment_station_bulletins

\section{Digital Commons Citation}

Keresztesy, Laszlo O., "Stability and strength properties of wood columns" (1974). West Virginia Agricultural and Forestry Experiment Station Bulletins. 630T.

https://researchrepository.wvu.edu/wv_agricultural_and_forestry_experiment_station_bulletins/712 @ WVU. It has been accepted for inclusion in West Virginia Agricultural and Forestry Experiment Station Bulletins by an authorized administrator of The Research Repository @ WVU. For more information, please contact ian.harmon@mail.wvu.edu. 


\section{Stability and \\ Strength Properties of Wood Columns}

Bulletin 630T

April 1974

Agricultural Experiment Station

West Virginia University

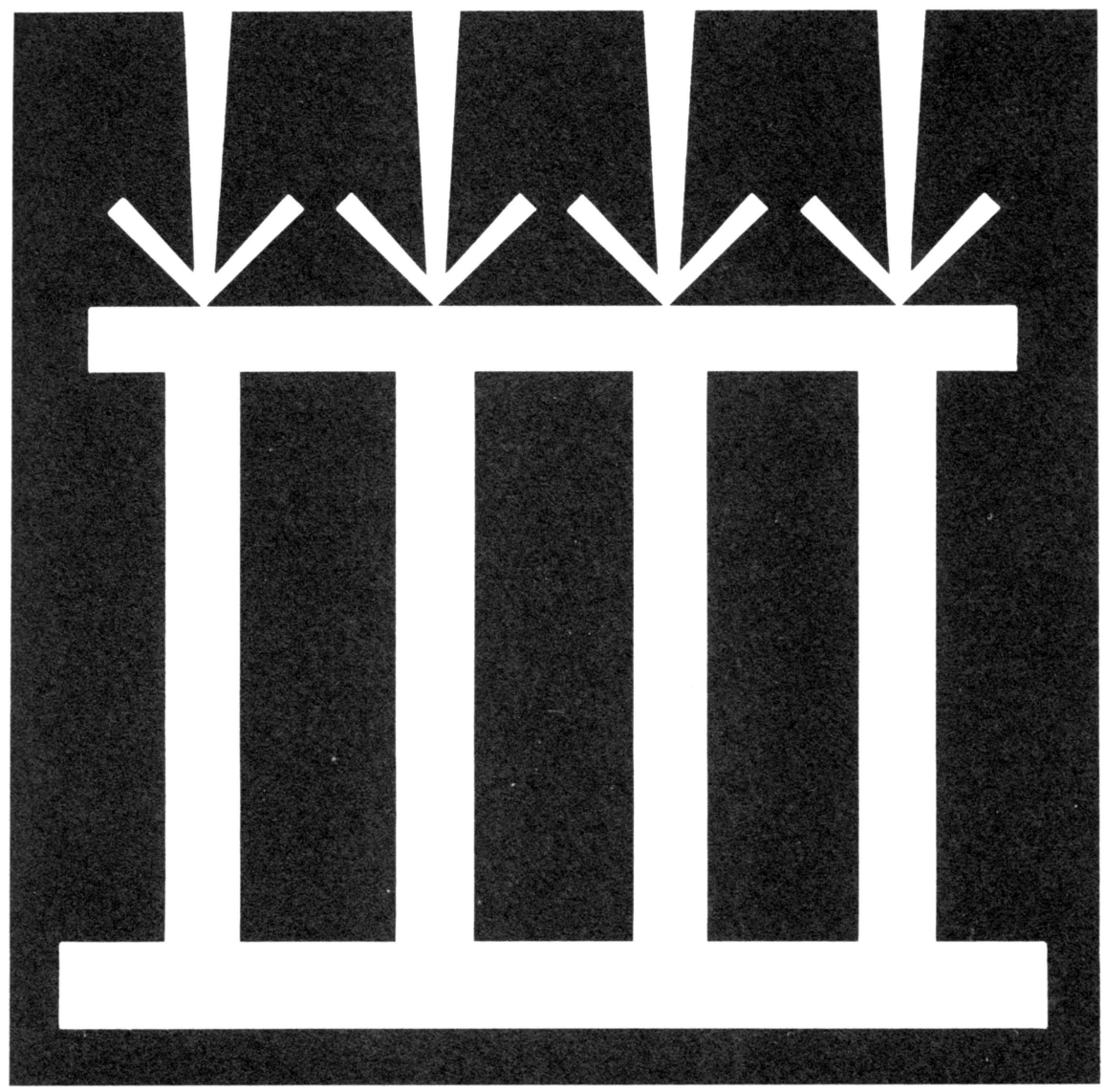




\section{[Blank Page in Original Bulletin]}




\title{
STABILITY AND STRENGTH PROPERTIES OF WOOD COLUMNS
}

\author{
by \\ Laszlo O. Keresztesy \\ Forest Research Scientist \\ Division of Forestry
}

West Virginia University Agricultural Experiment Station College of Agriculture and Forestry Homer C. Evans, Acting Director Morgantown 
[Blank Page in Original Bulletin] 


\section{ABSTRACT}

Centrically loaded columns do not exist in practice, and therefore, the eccentricity of the load should be considered in any realistic column theory. The general behavior of columns under eccentric load is influenced not only by the usual parameters i.e., column geometry, material characteristics, and load, but also by the loading process. The ultimate load bearing capacity for these columns is formulated in terms of limit state of stresses or limit state of stability or limit state of deformation. Since eccentrically loaded columns do not present the usual eigenvalue problem, the stability criterion for these columns is redefined and the limit state of stability is expressed in terms of stresses. When the behavior of the column is analyzed in terms of the loading process, it becomes apparent that the basic theories of Euler, Engesser, Von Karman, and Shanley are not contradictory but complimentary, and form particular solutions of a universal differential equation, which possess geometrical and material nonlinearity. Solution shows that columns with centric load represent only a singular case in the entire column analysis. Solution also provides a general picture of the behavior of columns under load and enables one to predict the ultimate load parameters and the nature of the failure. Nomograms based on predetermined deformation limit are presented to assist design. 


\section{[Blank Page in Original Bulletin]}




\section{CONTENTS}

Abstract............................ 3

Introduction. ......................... 7

Assumptions and Definitions $\ldots \ldots \ldots \ldots \ldots \ldots \ldots \ldots \ldots \ldots \ldots$

The General Column Theory $\ldots \ldots \ldots \ldots \ldots \ldots \ldots \ldots \ldots \ldots \ldots \ldots \ldots$

Equilibrium and Limit States...................... 11

The General Differential Equation...................... 14

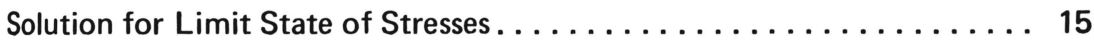

Elastic Materials .............................. 17

Plastic Materials . . . . . . . . . . . . . . . . . . 17

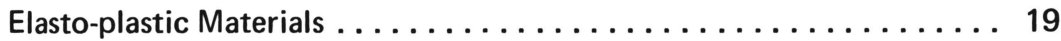

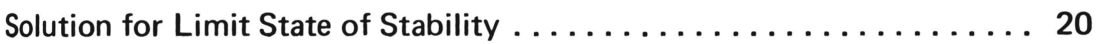

Separation of the Limits .......................... 22

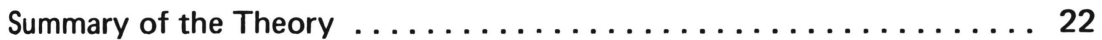

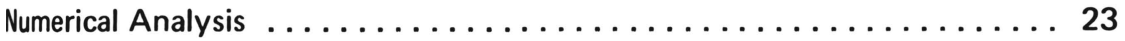

Description of the Method...................... 23

Discussion of the Results......................... 27

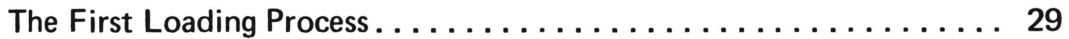

The Second Loading Process $\ldots \ldots \ldots \ldots \ldots \ldots \ldots \ldots \ldots \ldots \ldots$

The Third Loading Process . . . . . . . . . . . . . . . 35

Limitation of the Deformations.................... 35

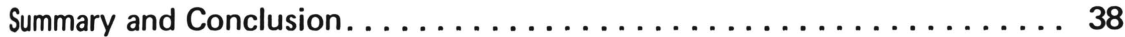

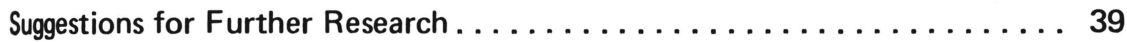

Bibliography............................ 40 


\section{[Blank Page in Original Bulletin]}




\section{INTRODUCTION}

Since Euler's classic investigation, the behavior of columns has retained the interest of many engineers. For a long time, however, the investigations were restricted to finding the buckling load for centrically loaded columns. Not much attention was paid to analyzing stress and strain patterns which may occur before the onset of buckling in the case of eccentric load. Moreover, it is surprising that such prominent scientists as Euler, Engesser, Von Karman, and Shanley did not obtain consistent results even for centrically loaded column.

Euler $^{1}$ (1744) assumed columns of perfectly elastic materials. Such columns do not bend under axial compressive forces as long as the force is less than the buckling load. For the buckling load and for the corresponding compressive stress he found:

$$
P_{c r}=\frac{\pi^{2}}{L^{2}} E I \quad \text { and } \quad \sigma_{c r}=\frac{\pi^{2}}{r^{2}} E
$$

Where $P_{c r}$ and $\sigma_{c r}$ represent the critical load and the critical stress respectively, $L$ is the effective length of the column, $I$ is the moment of inertia, $E$ is the modulus of elasticity, and $r$ is the slenderness ratio.

Engesser $^{2}$ (1889) also examined columns under axial compression, but assumed a nonlinear stress-strain diagram for the material of the columns. He stated the Euler's theory could be applied to nonlinear cases if the elastic modulus $E$ were replaced by the tangent modulus $E^{\prime}$. Specifically:

$$
E^{\prime}=\left.\frac{d \sigma}{d \epsilon}\right|_{\sigma=\sigma_{c r}} ; P_{c r}=\frac{\pi^{2}}{L^{2}} E^{\prime} L \text { and } \sigma_{c r}=\frac{\pi^{2}}{r^{2}} E^{\prime}
$$

Considère $^{3}$ (1899) pointed out that when a column under an axial load is stressed beyond the proportional limit, the column begins to bend. The compressive stresses on the concave side increase in a nonlinear manner, but on the convex side stress decreases are linear. Thus, the buckling load is given by:

$$
P_{c r}=\frac{\pi^{2}}{L^{2}} \bar{E} I \quad \text { where } \quad E^{\prime}<\bar{E}<E
$$

Von Karman ${ }^{4}$ (1910) added the analytical evaluation of $\bar{E}$, and supported Considère's theory by test results. He found the modulus $\bar{E}$, i.e., the double-modulus, to be:

$$
\bar{E}=\frac{E I_{1}+E^{\prime} I_{2}}{I_{1}+I_{2}}
$$

Where $I_{1}$ and $I_{2}$ denote the moment of inertia of those parts of the cross-section where the stresses increase and decrease respectively. 
Shanley ${ }^{5,6}$ (1946) concluded that at certain load values, compressive stresses increase on the convex side of the column, but at other load values compression may decrease or tension may develop. Consequently, the entire stress pattern depends on whether or not the load is constant or variable. Shanley also proved that the tangent modulus formula gives the maximum load at which a centrically loaded column remains straight. Loads between the Engesser and Karman loads result in a permanent bending deformation of the column. This means that the initially centric load becomes eccentric.

The purpose of this bulletin is to describe systematically the general behavior of thin-walled columns, concentrating on strength and stability problems in the case of eccentric load. Some important points that need to be mentioned in advance are:

1. Columns at centric load are a special case of the general problem. In fact, axially loaded columns do not exist, and even if one assumes such columns the load becomes eccentric when it exceeds the Engesser value. This suggests the need for a general theory of eccentrically loaded columns that includes centric loading as a special case. The significance of this suggestion is reflected in many bridge and building codes in Europe ${ }^{7,8}$ that require consideration of a so-called accidental eccentricity in any column design. For wooden structures, where the inaccuracy in the construction is of much higher degree than in steel structures, the eccentricity of the load plays an even more important role.

2. Under eccentric load, the load-bearing capacity of a column is much less that that predicted by the Euler or Engesser theories. Moreover, both the critical load and the stress distribution will depend instead on two parameters, i.e., the magnitude of the load and its eccentricity. Many combinations of these may cause either critical stress or buckling. The fact that critical stresses may occur either earlier or later than buckling is of vital importance because the first case involves a strength problem, and the second case a stability problem.

3. Compressive stress-strain diagrams for wood show a definite inelastic tendency, where no proportional limit exists; for tension, however, and particularly for small loads, these diagrams are essentially linear. These facts suggest the need for an ultimate load theory based on an assumed elastoplastic state of the column.

In order to describe the general behavior of thin-walled columns, an analytical and a numerical method is presented. The latter, based on a step-by-step process, also will provide information for practical design. Although the theory presented here, because of its generality, can be applied to any symmetrical cross-section, the numerical analysis will be restricted to box columns. 


\section{ASSUMPTIONS AND DEFINITIONS}

It will be assumed that:

1. The unloaded column is straight, and is supported by hinges (Fig. 1A). The hinges prevent lateral displacements at the ends but allow rotation and axial deformation.

2. The column has an arbitrary cross-section which is constant throughout the length. The cross-section has two axes of geometric and elastic symmetry.

3. The loading consists of one single concentrated load acting in eccentric position. The eccentricity is considered along one of the axes of symmetry (Fig. 1B).
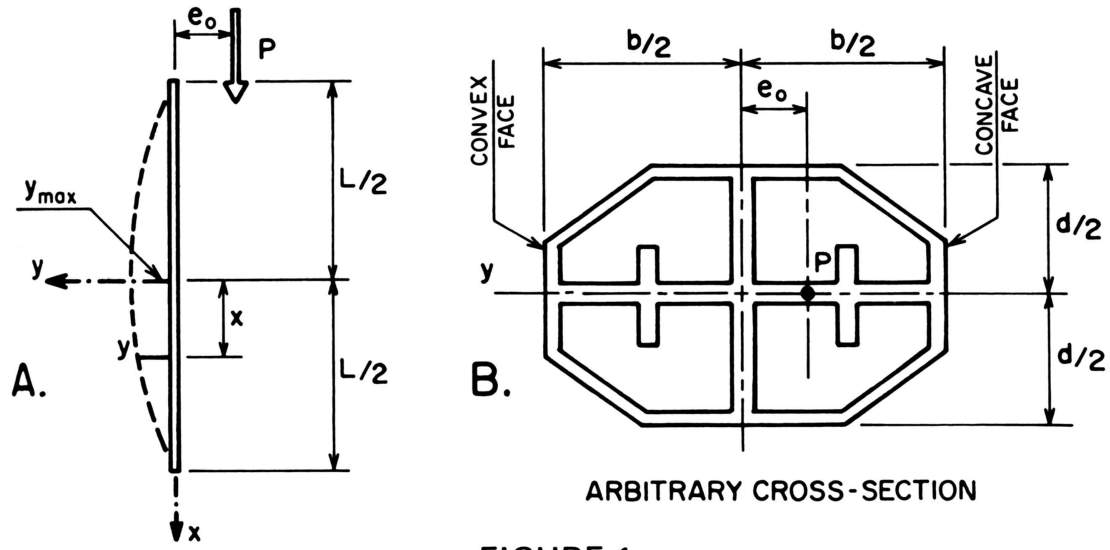

ARBITRARY CROSS-SECTION

FIGURE 1

4. The cross-sections of the column remain planes during deformation even if the stresses are beyond the proportional limit.

5. The material of the column is elasto-plastic and characterized by a stress-strain diagram shown in Fig. 2. Thus along the concave side of the column, where a monotone stress increase occurs, the stress-strain relation is assumed to be nonlinear and given by:

$$
\epsilon_{1}=\epsilon_{1}\left(\sigma_{1}, \sigma_{u}, E\right)
$$

Along the convex side, however, the stress may increase or decrease. The stress-strain relation for increasing stresses is nonlinear and described by:

$$
\epsilon_{2}=\epsilon_{2}\left(\sigma_{2}, \sigma_{u}, E\right)
$$




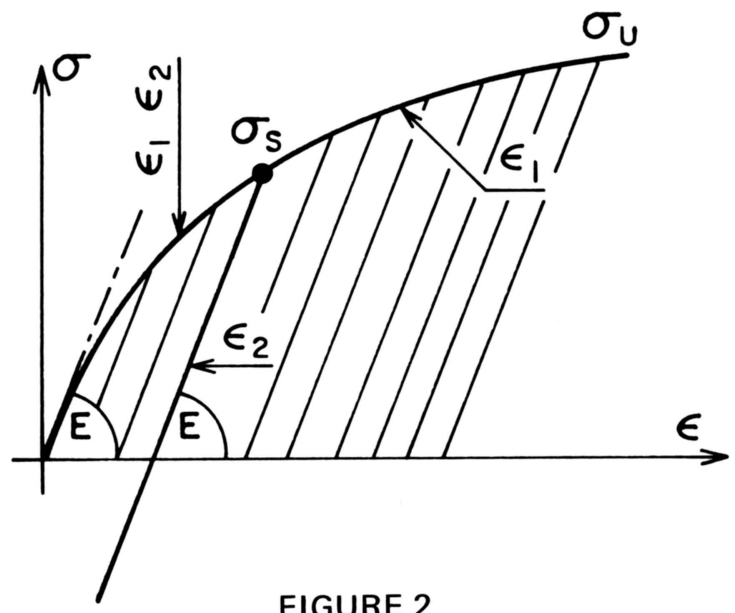

FIGURE 2

For decreasing stresses the relation is linear and characterized by:

$$
\epsilon_{2}=\epsilon_{2}\left(\sigma_{2}, \sigma_{1}, \sigma_{S}, E\right)
$$

In these equations, $\epsilon_{1}, \sigma_{1}$ and $\epsilon_{2}, \sigma_{2}$ denote the strains and stresses in the concave side and in the convex side of the column respectively. $\sigma_{u}$ is the ultimate stress for compression; $\sigma_{t}$ is the permissible tearing stress for bending; $E$ denotes the modulus of elasticity for compression; and $\sigma_{S}$ indicates that particular value of $\sigma_{2}$ from which the stress decreasing phenomenon starts. Thus the entire stress-strain diagram incorporates an envelope curve and a family of straight lines (Fig. 2).

As the load or the eccentricity exceeds certain values, the column becomes subjected to a critical condition. Three independent conditions are defined: the limit state of stresses, the limit state of stability, and limit state of deformation.

1. Limit state of stresses occurs in the column if the compressive stress in the middle section ( $x=0$ in Fig. 1.A) reaches the ultimate value $\sigma_{u}$ or if the tensile stress in the same cross-section exceeds the allowable tensile stress for bending $\sigma_{\uparrow}$.

2. Limit state of stability occurs at the onset of buckling. This limit state can be formulated in terms of stresses. Thus failure in stability occurs at a condition when an infinitesimal increment of the load or eccentricity will result in a finite value of stresses. This stability limit can be reached only if the column has not previously failed owing to the limit state of stresses. 
3. For slender columns and for large eccentricities, the deformation of the column may reach a certain value that cannot be accepted for practical reasons. Therefore, the maximum deformation of the column should be limited. The corresponding limit will be called the limit state of deformation which, however, does not indicate actual failure of the column. Unfortunately, this limit is not specified in the present codes and specifications for wood structures. Therefore, in this study, the limit state of deformation will be assumed arbitrarily to be L/400th of the effective length.

In order to consider all the possible connecting pairs of the two parameters (load and eccentricity), the term "loading process" is defined. Loading process refers to the order of loading, that may include 1) constant load with monotone increasing eccentricity, 2) constant eccentricity with monotone increasing load, and 3) simultaneously increasing load and eccentricity.

The limit state of stresses and limit state of stability will be analyzed with regard to each of the loading processes.

\section{THE GENERAL COLUMN THEORY}

\section{EQUILIBRIUM AND LIMIT STATES}

The equilibrium in any arbitrary cross-section of the column can be formulated based on the equality of the external and internal forces and moments (Fig. 3.), i.e.:

$$
\begin{aligned}
& P=\frac{1}{2}\left[\sigma_{1}+\sigma_{2}\right] A \\
& P e=\frac{1}{2}\left[\sigma_{1}-\sigma_{2}\right] Z
\end{aligned}
$$

where: $A$ is the area of the cross-section

$Z$ is the section modulus

$P$ is the external load

$e$ is the eccentricity of the load

Solving the equations of equilibrium for the fiber stresses we obtain:

$$
\left.\begin{array}{ll}
\text { in the concave side, } & \sigma_{1}=\frac{P}{A}+\frac{P e}{Z} \\
\text { in the convex side, } & \sigma_{2}=\frac{P}{A}-\frac{P e}{Z}
\end{array}\right\}
$$

Based on the notation of Fig. 1.B., $I=Z b / 2$ but also $I=A i^{2}$, where $I$ and $i$ denote the moment of inertia and the radius of gyration respectively. Both quantities are considered with respect to the axis of symmetry that is normal to 


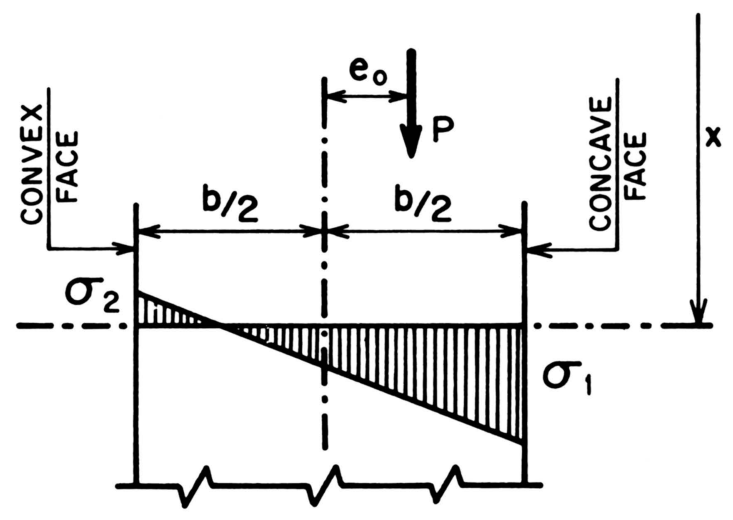

FIGURE 3

the plane of bending. From these relations, one can establish that $Z=2 \mathrm{Ai}^{2} / \mathrm{b}$, which after substituting in (8) and introducing the concept of average stress, defined as:

$$
\sigma_{\mathrm{av}}=\frac{P}{A}
$$

leads finally to:

$$
\left.\begin{array}{l}
\sigma_{1}=\sigma_{\mathrm{av}}(1+\mathrm{es}) \\
\sigma_{2}=\sigma_{\mathrm{av}}(1-\mathrm{es})
\end{array}\right\}
$$

where:

$$
s=b / 2 i^{2}
$$

is constant for a given column. If limit state of stresses is considered, then $\sigma_{1}=\sigma_{u}$ and $\sigma_{2}=\sigma_{\uparrow}$, and (10) becomes:

$$
\left.\begin{array}{l}
\sigma_{u}=\sigma_{a v}(1+e s) \\
\sigma_{t}=\sigma_{a v}(1-e s)
\end{array}\right\}
$$

Consequently each corresponding $\mathrm{P}$ and e pair of parameters which satisfy (12) will cause limit state of stresses in the column. Solving (12) for the eccentricity one finds:

$$
\left.\begin{array}{l}
e=\left[\frac{\sigma_{u}}{\sigma_{\mathrm{av}}}-1\right] \frac{1}{\mathrm{~s}} \\
e=\left[1-\frac{\sigma_{t}}{\sigma_{\mathrm{av}}}\right] \frac{1}{\mathrm{~s}}
\end{array}\right\}
$$


These equations provide upper limits for the eccentricity related to limit state of stresses. The eccentricity, however, consists of two parts. First, the initial eccentricity $e_{o}$ which is constant during one cycle of the loading process. The second part includes the deformation of the column $y$, which varies and reaches the maximum at the middle section of the column. Thus,

and if $\left.x=0, \quad \begin{array}{l}e=e_{0}+y \\ e=e_{0}+y_{\max }\end{array}\right\}$

Therefore, at the middle section, which will be termed the critical section:

$$
\left.\begin{array}{l}
y_{\text {max }}=\left[\frac{\sigma_{u}}{\sigma_{a v}}-1\right] \frac{1}{s}-e_{o} \\
y_{\text {max }}=\left[1-\frac{\sigma_{t}}{\sigma_{a v}}\right] \frac{1}{s}-e_{o}
\end{array}\right\}
$$

If the load $P$ or the eccentricity $e_{o}$ increases monotonously, each pair of parameters will result in a $y_{\max }$. Therefore, any of the three loading processes will yield a sequence:

$$
\begin{aligned}
& \mathrm{y}_{\max 1}, \mathrm{y}_{\max 2}, \mathrm{y}_{\max 3} \cdots \mathrm{y}_{\max \mathrm{n}} \cdots \\
& \text { where } \mathrm{y}_{\max \mathrm{n}-1}<\mathrm{y}_{\max \mathrm{n}}
\end{aligned}
$$

where each element of the sequence is related to one pair of parameters.

If for consecutive steps of the loading process the corresponding $y_{\max }$ elements have finite values, that particular $y_{\max }$ (if any) that corresponds to the limit stresses, will provide the limiting deformation of the column in a stable equilibrium configuration. This condition of the column was defined earlier as the limit state of stresses, and the corresponding $P$ and $e_{o}$ values are termed limiting parameters.

If for consecutive steps of the loading process, the $y_{\max }$ elements increase at an extremely high rate so that any infinitesimal increment of the load or of the eccentricity results in a finite increment in $y_{\text {max }}$, the column is in an unstable equilibrium configuration. For such rapid increases of the deformation, the corresponding fiber stress also increases rapidly. The failure of the stability (buckling) is now identified with that particular condition of the column at which for any infinitesimal increment in the load or in the eccentricity the related change in the fiber stress will have a finite value. This condition was defined earlier as the limit state of stability, which, however, does not represent the usual eigenvalue problem. The loading step at which the stability fails will be called the critical step, and the corresponding parameters are termed critical parameters. 


\section{THE GENERAL DIFFERENTIAL EQUATION}

With certain combinations of the $P$ and $e_{o}$ parameters, the column will begin to bend. Following (15), bending occurs if the parameters satisfy the relation:

$$
e_{o}<\left[\frac{\sigma_{u}}{\sigma_{o v}}-1\right] \frac{1}{s}
$$

During bending, elongation occurs in the convex face of the column, while in the concave face contraction takes place. These deformations are expressed in terms of fiber strains. Consider an infinitesimal element, $\Delta x$, of the column bounded by two horizontal planes. Based on Fig. 4 , the following relation can be established:

$$
\frac{\Delta x}{R}=\frac{\Delta x\left(\epsilon_{1}-\epsilon_{2}\right)}{b \cdot \cos \alpha}
$$

or

$$
\frac{1}{R}=\frac{\epsilon_{1}-\epsilon_{2}}{b \cdot \cos \alpha}
$$

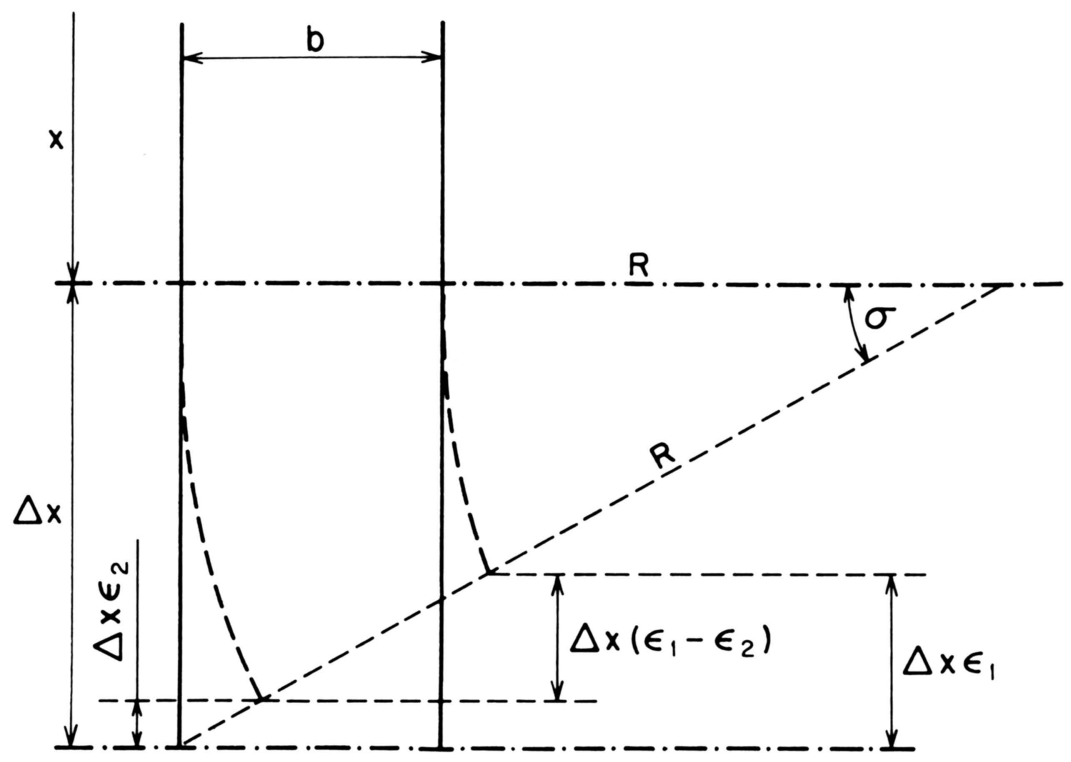

FIGURE 4 
therefore

$$
\frac{1}{R}=\frac{\epsilon_{1}-\epsilon_{2}}{\sqrt{b^{2}-(\Delta x)^{2}\left(\epsilon_{1}-\epsilon_{2}\right)^{2}}}
$$

The normal strains $\epsilon_{1}$ and $\epsilon_{2}$ are functions of the stresses and these in turn are related to the load and eccentricity. Since the load is hidden in $\sigma_{\mathrm{ov}}$, it is convenient to introduce a function $\psi$ in the form of:

$$
\psi\left(\sigma_{\mathrm{ov}}, y, e_{o}\right)=-\frac{\epsilon_{1}-\epsilon_{2}}{\sqrt{\mathrm{b}^{2}-(\Delta \mathrm{x})^{2}\left(\epsilon_{1}-\epsilon_{2}\right)}}
$$

The curvature, on the other hand, is in a known relation with the deformation $y$, so that:

$$
\frac{y^{\prime \prime}}{\left[1+y^{\prime 2}\right]^{3 / 2}}=\psi\left(\sigma_{a v}, y, e_{o}\right)
$$

from which:

$$
y^{\prime \prime}-\psi\left(\sigma_{a v}, Y, e_{0}\right)\left[1+Y^{\prime 2}\right]^{3 / 2}=0
$$

Equation (18) is the general differential equation for the entire column problem; it includes all of the particular solutions:

a. If the deformations are small, a geometric linearization is possible by introducing $(d x)^{2}=0$ and $\left(y^{1}\right)^{2}=0$

b. In case of centric load $e_{0}=0$

c. The function $\psi$ can be formulated for elastic, plastic, or elasto-plastic material behavior.

d. The function $\psi$ can also be formulated to obtain solutions for the limit state of stresses or for the limit state of stability.

\section{SOLUTION FOR LIMIT STATE OF STRESSES}

If limiting stresses occur in the column it can be assumed that the deformations are small. Then the governing differential equation (18) reduces to:

where:

$$
\left.\begin{array}{l}
y^{\prime \prime}=\frac{1}{b} \psi\left(\sigma_{a v}, y, e_{o}\right) \\
\psi\left(\sigma_{a v}, y, e_{o}\right)=\epsilon_{2}-\epsilon_{1}
\end{array}\right\}
$$


In solving (19) one may consider $z=\frac{1}{2}\left(\frac{d y}{d x}\right)^{2}$ as a new variable.

Then,

$$
\frac{d z}{d x}=\frac{d y}{d x} \cdot \frac{d^{2} y}{d x^{2}}
$$

and

$$
\frac{d^{2} y}{d x^{2}}=\frac{d z}{d x} \cdot \frac{d x}{d y}=\frac{d z}{d y}=\frac{1}{b} \psi\left(\sigma_{o v}, y, e_{o}\right)
$$

After integration

$$
z=\frac{1}{b} \int \psi\left(\sigma_{a v}, y, e_{o}\right) d y+C_{1}
$$

and

$$
\frac{d y}{d x}=\sqrt{\frac{2}{b} \int \psi\left(\sigma_{a v}, y, e_{o}\right) d y+C_{1}}
$$

The variables can be separated to obtain:

$$
x=\int \frac{d y}{\sqrt{\frac{2}{b} \int \psi\left(\sigma_{a v}, y, e_{o}\right) d y+C_{1}}}+C_{2}
$$

where $C_{1}$ and $C_{2}$ are integral constants. Based on Fig. 1.A. the following boundary conditions are considered:

$$
\begin{aligned}
& \text { a. if } x=0, y=y_{\max } \text { and } y^{\prime}=0 \\
& \text { b. if } x=\frac{L}{2}, y=0
\end{aligned}
$$

Based on $a, \quad y^{\prime}=\sqrt{\frac{2}{b} \int \psi\left(\sigma_{a v}, y, e_{0}\right) d y+C_{1}}=0$

or

$$
\int \psi\left(\sigma_{o v}, y, e_{o}\right) d y+c=\int_{y_{\max }}^{y} \psi\left(\sigma_{o v}, y, e_{o}\right) d y
$$

and from $b$,

$$
\frac{L}{2}=\int_{0}^{y_{\max }} \frac{d y}{\sqrt{\frac{2}{b} \int_{y_{\max }}^{y} \psi\left(\sigma_{a v}, y, e_{o}\right) d y}}
$$


Introducing now the slenderness ratio $r=L / i$ and the constant $s$ from (11), (20) becomes:

$$
r=2 \sqrt{s} \int_{0}^{y_{\max }} \frac{d y}{\sqrt{\int_{y_{\max }}^{y} \psi\left(\sigma_{o v}, y, e_{o}\right) d y}}
$$

In order to perform these integrations, the function $\psi\left(\sigma_{o v}, y, e_{0}\right)$ must be established for different material characteristics.

\section{Elastic Material}

According to Euler's theory, the stresses increase on both faces of the column in a linear manner (Fig. 5), so that:

$$
\epsilon_{1}=\frac{\sigma_{1}}{E} \text { and } \epsilon_{2}=\frac{\sigma_{2}}{E}
$$

Substituting $\sigma_{1}$ and $\sigma_{2}$ from (10),

$$
\psi\left(\sigma_{\mathrm{av}}, y, e_{o}\right)=\epsilon_{2}-\epsilon_{1}=-\frac{2 P}{A E} s\left(e_{o}+y\right)
$$

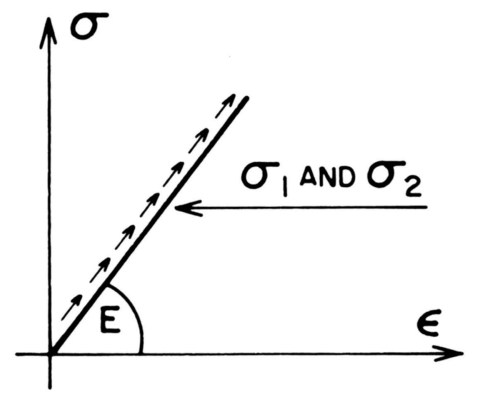

FIGURE 5

\section{Plastic Material}

The Engesser theory assumes a nonlinear stress-strain relation in both faces of the columns. This can be very well approximated by a third order parabola (Fig. 6) given by the equation:

$$
\epsilon=\frac{\sigma}{E}+a\left[\frac{\sigma}{E}\right]^{3}
$$

where "a" is constant for a given material. In general "a" depends on the 


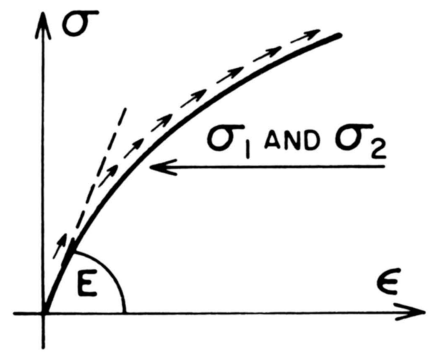

FIGURE 6

modulus of elasticity. For many of the structural timbers, "a" is approximately equal to $10^{-4}$.

The strains are:

$$
\epsilon_{1}=\frac{\sigma_{1}}{E}+a\left[\frac{\sigma_{1}}{E}\right]^{3} \text { and } \epsilon_{2}=\frac{\sigma_{2}}{E}+a\left[\frac{\sigma_{2}}{E}\right]^{3}
$$

and substituting $\sigma_{1}$ and $\sigma_{2}$ from Eg. (10) one has:

$$
\psi\left(\sigma_{a v}, y, e_{o}\right)=-\frac{2 P}{A E} s\left(e_{o}+y\right)-2 a\left[\frac{P}{A E}\right]^{3}\left[3 s\left(e_{o}+y\right)+s^{3}\left(e_{o}+y\right)^{3}\right]
$$

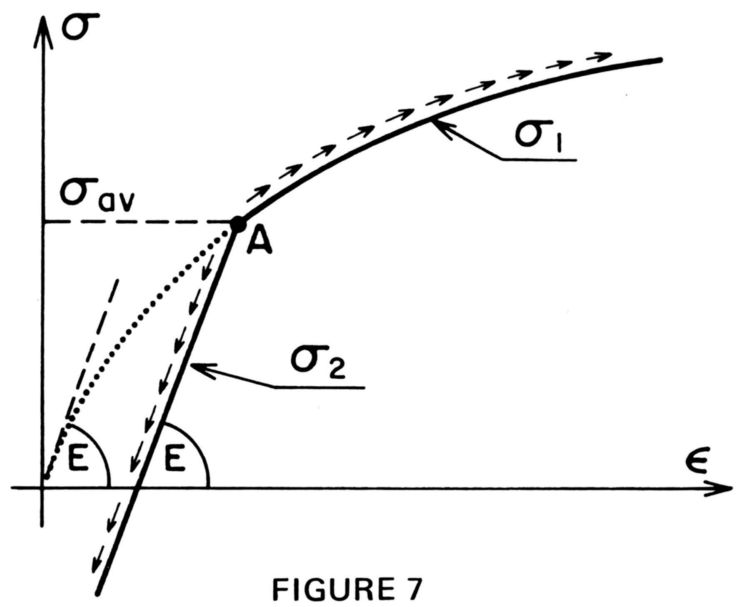




\section{Elasto-Plastic Material}

Von Karman's Assumption

If the stresses increase on the concave face and decrease on the convex face, then the stress decrease in general obeys Hooke's Law. The corresponding stress-strain diagram is shown in Fig. 7. The position of the straight line, for stress decrease, depends on the point $A$, which is a function of the load $P$. Assuming a cubic parabola for stress increase:

$$
\epsilon_{1}=\frac{\sigma_{1}}{E}+a\left[\frac{\sigma_{1}}{E}\right]^{3} \text { and } \epsilon_{2}=\frac{\sigma_{2}}{E}+a\left[\frac{\sigma_{a v}}{E}\right]^{3}
$$

Substituting $\sigma_{1}$ and $\sigma_{2}$ from Eg. (10):

$$
\begin{aligned}
\psi\left(\sigma_{\mathrm{av}}, y, e_{o}\right)=- & \frac{2 P}{A E} s\left(e_{o}+y\right)+a\left[\frac{P}{A E}\right]^{3}\left[3 s\left(e_{o}+y\right)-\right. \\
& \left.3 s^{2}(e+y)^{2}-s^{3}(e+y)^{3}\right]
\end{aligned}
$$

\section{Shanley's Assumption}

According to Shanley assumptions, the stresses in the concave side increase, but in the convex side either stress increase or stress decrease may occur. This relation is shown in Fig. 8. If the stresses in the convex side increase, the behavior of the column is analogous to the Engesser theory, and the function $\psi$ is given by (23). If, however, stress decreases occur in the convex face, the phenomenon is controlled by the Von Karman theory, and (24) applies.

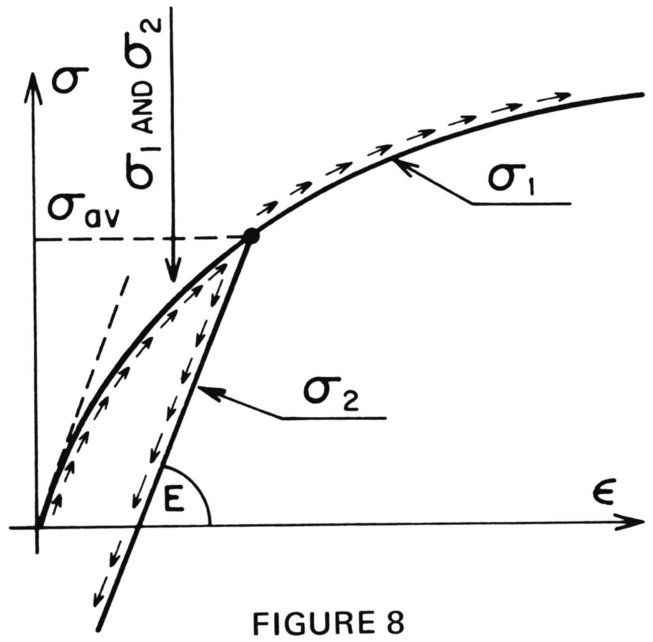


If the behavior of the material is specified, i.e., the approximate function $\psi$ is selected, then for any given slenderness ratio $r$ the corresponding $y_{\max }$ deformation can be obtained from (21). On the other hand, if $\mathrm{y}_{\max }$ is assumed and satisfies the condition of limiting stresses, i.e.:

$$
y_{\max }=\left[\frac{\sigma_{u}}{\sigma_{\mathrm{av}}}-1\right] \frac{1}{s}-e_{o}
$$

the integration of (21) provides a function for any selected slenderness ratio. It should be noted that $\sigma_{1}$ is a function of $\sigma_{\mathrm{ov}}, y$, and $e_{o}$; and $P$ is hidden in $\sigma_{\mathrm{ov}}$, and $y$ vanishes after substituting the limits into the outer integral of (21). Consequently, the function obtained will involve only two variables, $P$ and $\mathrm{e}_{\mathrm{o}}$, and can be written as:

$$
P=f\left(e_{0}\right)
$$

Each combination of the parameters $P$ and $e_{o}$ that satisfies this function is a solution of the problem, and will create limit state of stresses in the column as shown in Fig. 9. A particular case of $e_{0}=0$ provides a solution for centric compression.

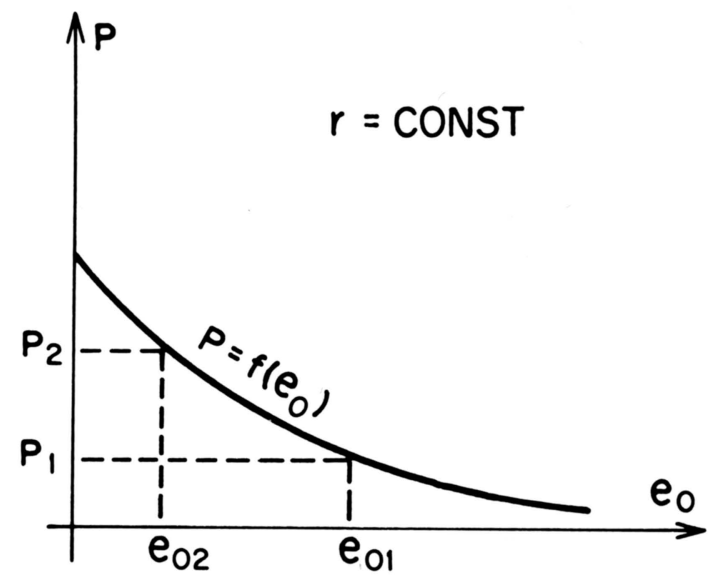

FIGURE 9

\section{SOLUTION FOR THE LIMIT STATE OF STABILITY}

The limit state of stability was defined earlier as the condition of the column when an infinitesimal increment of the load or eccentricity result in finite fiber stresses. 
Mathematically, if $\mathbf{P}=$ const, this state is equivalent to the condition of $d \sigma /$ de $_{o} \rightarrow \infty$ as shown in Fig. 10; or in a more convenient way:

$$
\frac{d e_{0}}{d \sigma}=0
$$

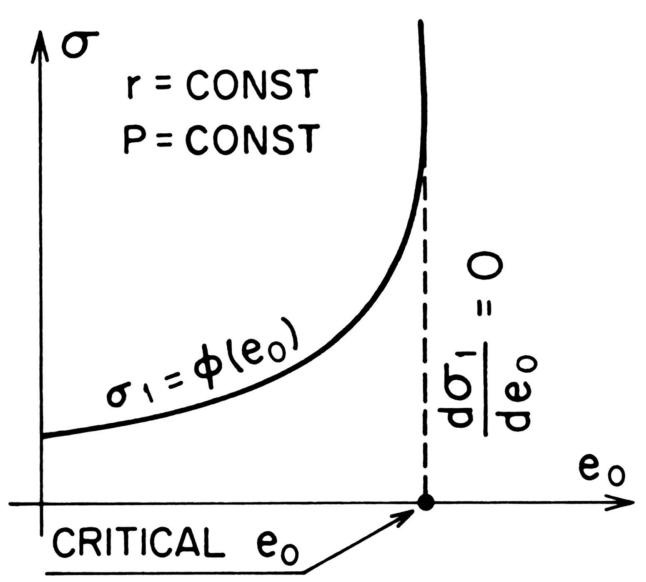

FIGURE 10

Thus, the problem includes finding the function $\sigma=\phi\left(e_{0}\right)$ or the equivalent function:

$$
e_{0}=F(\sigma)
$$

This function can be derived for any given slenderness ratio and material characteristics by integrating (21).

For the limit state of stability, however, the parameters $P$ and $e_{o}$ are not related to the ultimate stress, because at the onset of buckling, the fiber stresses are not equal to the limiting stresses. Here the parameters are functions of the real fiber stresses $\sigma_{1}$ and $\sigma_{2}$. Thus for the limit of integration one obtains:

$$
y_{\text {max }}^{*}=\left[\frac{\sigma_{1}}{\sigma_{a v}}-1\right] \frac{1}{s}-e_{0}
$$

When this limit is substituted into (21), the variable $y$ will not vanish; it can be expressed, however, in terms of $\sigma_{1}$. Since $P$ remains hidden in $\sigma_{\mathrm{ov}}$, the relation obtained after integration will be in the form:

$$
e_{0}=g\left(\sigma_{1}, P\right)
$$


The exact method of finding extremes for this function is extremely difficult, and a parametric solution is more convenient. This means for each $\mathbf{P}=$ const an $e_{0}=F\left(\sigma_{1}\right)$ function is established, and (25) will yield a critical eccentricity for a constant $P$ and constant $r$ as shown in Fig. 10.

It must be pointed out, however, that deformation for slender columns and near the onset of buckling are relatively large, and a linearized theory based on (19) and (21) provides only a rough approximation. The exact solution is given by the more general differential equation (18). If the material characteristics are specified and the slenderness ratio is given, (18), in principle, can be solved; and the $e_{0}=F\left(\sigma_{1}\right)$ can be developed and the critical eccentricity can be obtained from (25).

In practice, however, wood columns are constructed to possess not very high slenderness ratios. For slender columns, as it will be shown later, the loading parameters are always controlled by deformation limitation. Since this limitation permits small deformations, a quasi linear theory is applicable. In a quasi linear theory, small deformations are considered, thus geometrical non linearity is not involved; material non linearity, however, is included.

\section{Separation of the Limits}

The theory elaborated above enables one to determine the limit state of stresses and the limit state of stability. It is also important, however, to predict which of these states occurs earlier in the loading process for a given column.

From Fig. 9 and the related analysis, paired paramenters $P$ and $e_{0}$ are obtained. Each pair defines a limit state of stresses. In the application of the theory, a pair of suitable parameters $P_{L}$ and $e_{o L}$ is selected. From the particular parametric solution corresponding to $P_{L}$ (Fig. 10), the critical eccentricity $e_{o c}$ can be obtained according to the related analysis. If $e_{o c}>e_{o L}$ the limit state is attained at a lower stress level than the critical stress, then $P_{L}$ and $e_{o L}$ are acceptable. If, however, $e_{\mathrm{oc}}<\mathrm{e}_{\mathrm{oL}}$ the stability limit is obtained at a lower stress level, and the load must be reduced. In this instance, based on the particular parametric solution (Fig. 10) for which $\mathrm{e}_{\mathrm{oL}}=\mathrm{e}_{\mathrm{oc}^{\prime}}$ a new load can be obtained. Or, as an alternative, retaining the original load, a new eccentricity can be selected.

\section{SUMMARY OF THE THEORY}

This analytical solution of the column problem frequently involves mathematical difficulties, particularly when goemetric nonlinearity is involved. Even if the linearized version of (18) is employed, (21) leads to elliptic integrals when the stress-strain relation ceases to be elastic. Therefore, the theoretical analysis cannot conveniently provide comprehensive solutions that a designer may require. For this information a numerical method is more expedient. The aim here has been to show the existence of a universal solution. 
The theory is perfectly general. It includes solutions for centric and eccentric load, for linear and nonlinear material behavior, for small and large deformations, and for strength and for stability problems. In the comprehensive differential equation (18), each basic theory outlined in the introduction holds in its original form. In case of zero eccentricity, the results obtained from (21) are identical to those of Euler, Engesser, Von Karman, and Shanley. Consequently, these apparently controversial theories are not actually in conflict since they form particular solutions of (18). It will be shown in the numerical analysis that even if the load is eccentric, the column behaves similarly to that described by the earlier theories. For eccentric load, however, the behavior of the column follows the Engesser, Karman, or Shanley pattern depending entirely on the loading process. Consequently, in the entire column problem, each of the basic theories has its own domain of validity.

\section{NUMERICAL ANALYSIS}

The analytical solution of the quasi linear column problem presents mathematical difficulties; moreover, the large number of individual solutions requires rewriting it in a computerized numerical form.

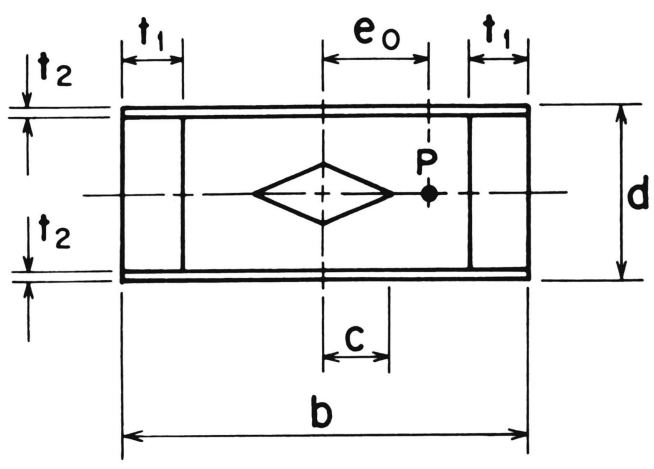

FIGURE 11

\section{DESCRIPTION OF THE METHOD}

The numerical method is applied to analyze box columns (Fig. 11) and includes the following objectives:

a. to examine the occurrence and order of the limit state of stresses, stability and deformation

b. to analyze the general behavior of these columns

c. to develop practical design information for box columns 
In order to perform the numerical analysis on realistic data, an array of columns was generated with the usual column height of $\mathbf{8 . 0 0}$ feet. The elements were generated to possess slenderness ratios $(r)$ in the range from $r=5$ to $r=220$, with equal increments of 10 between $r=10$ and $r=200$.

The analysis was based on an elasto-plastic stress-strain diagram (Fig. 2) which was characterized by the following equations:

On the concave face of the column: $\epsilon_{1}=\frac{\sigma_{1}}{E}\left[1+\left(\frac{\sigma_{1}}{12500}\right)^{2}\right]$

On the convex face for compression: $\epsilon_{2}=\frac{\sigma_{2}}{E}\left[1+\left(\frac{\sigma_{2}}{12500}\right)^{2}\right]$

On the convex face for tension: $\quad \epsilon_{2}=\frac{\sigma_{2}}{E}+\frac{\sigma_{S}}{E}\left(\frac{\sigma_{S}}{12500}\right)^{2}$

The material properties involved in these equations were based on average values obtained from experiment, and their numerical values were considered as follows:

$\begin{array}{llr}\text { Young's modulus for compression: } & E=1,250,000 \text { psi } \\ \text { Ultimate compressive stress: } & \sigma_{u}= & 5,000 \text { psi } \\ \text { Allowable tensile stress: } & \sigma_{\uparrow}= & 2,000 \text { psi }\end{array}$

The numerical analysis developed here included a step-by-step technique. The individual steps were considered small enough in order to follow the quasi linear nature of the problem. In order to avoid all the unnecessary repetition in computation, a combined operation was developed that included all three loading processes. The rough framework of the entire operation consisted of three nested loops (Fig. 12A).

Detailed computation for each step of the inner loop includes the following sequence of operations:

a. The shape of the deformed column axis is estimated first. Since the deformation is symmetric about the origin of the coordinate system (Fig. 1), only the half length of the column is analyzed. A good approximation was achieved by dividing the half length into 100 equal intervals $(\Delta x=L / 200)$, and estimating the deformations $y_{i}$ at each of the corresponding absissas $x_{i}$, where i varies from 1 to 100 .

b. Knowing the initial eccentricity $e_{o}$ and the load $P$, the total eccentricity becomes $e_{i}=e_{0}+y_{i}$, and the fiber stresses $\sigma_{1 i}$ and $\sigma_{2 i}$ are obtained from (10). The fiber strains $\epsilon_{1 i}$ along the concave face are computed from (28). Along the convex face, however, the stresses $\sigma_{2 i}$ may increase or, at some point, 


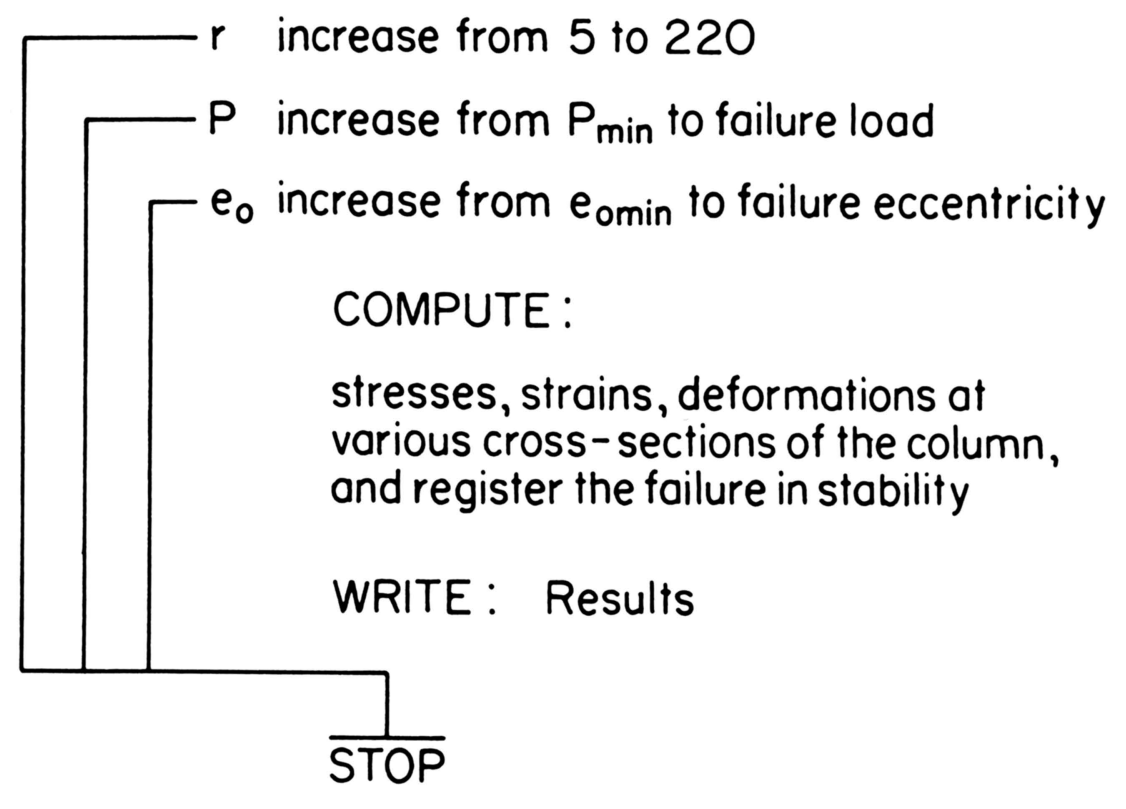

FIGURE 12A

decrease. Therefore, the fiber strains $\epsilon_{2 i}$ are computed either from (29) or (30). The turning point, if any, occurs when the increment of $\sigma_{2 i}$ produced by two consecutive steps of the loop changes from positive to negative.

c. Once the fiber strains are obtained, the function $\psi$ and the second derivatives $y_{i}^{\prime \prime}$ of the deformed column axis can be computed from (19). A numerical integration technique, based on the finite differences approach, is introduced to provide the solution for the differential equation (19); i.e., to provide the array $\mathbf{y}_{\mathbf{i}}$.

d. At this point, the shape of the deformed column evidently will differ from that estimated in paragraph a. Consequently, the entire procedure of paragraphs $\mathrm{b}$ and $\mathrm{c}$ is repeated iteratively until the discrepancy between two consecutive arrays becomes negligible. After determining the final shape of the column, corresponding stresses and strains can be computed at any cross-section.

The flow chart of the inner loop is shown in Fig. 12B.

During the execution of the inner loop (Fig. 12B), the column may attain a state at which, for any further arbitrarily small increment of eccentricity, a finite value of stress obtains. This condition was defined earlier as the limit state of stability and characterized by (25). The computer registers this condition, and terminates the execution of the inner loop. If the limit state of stresses occurs 
ธั

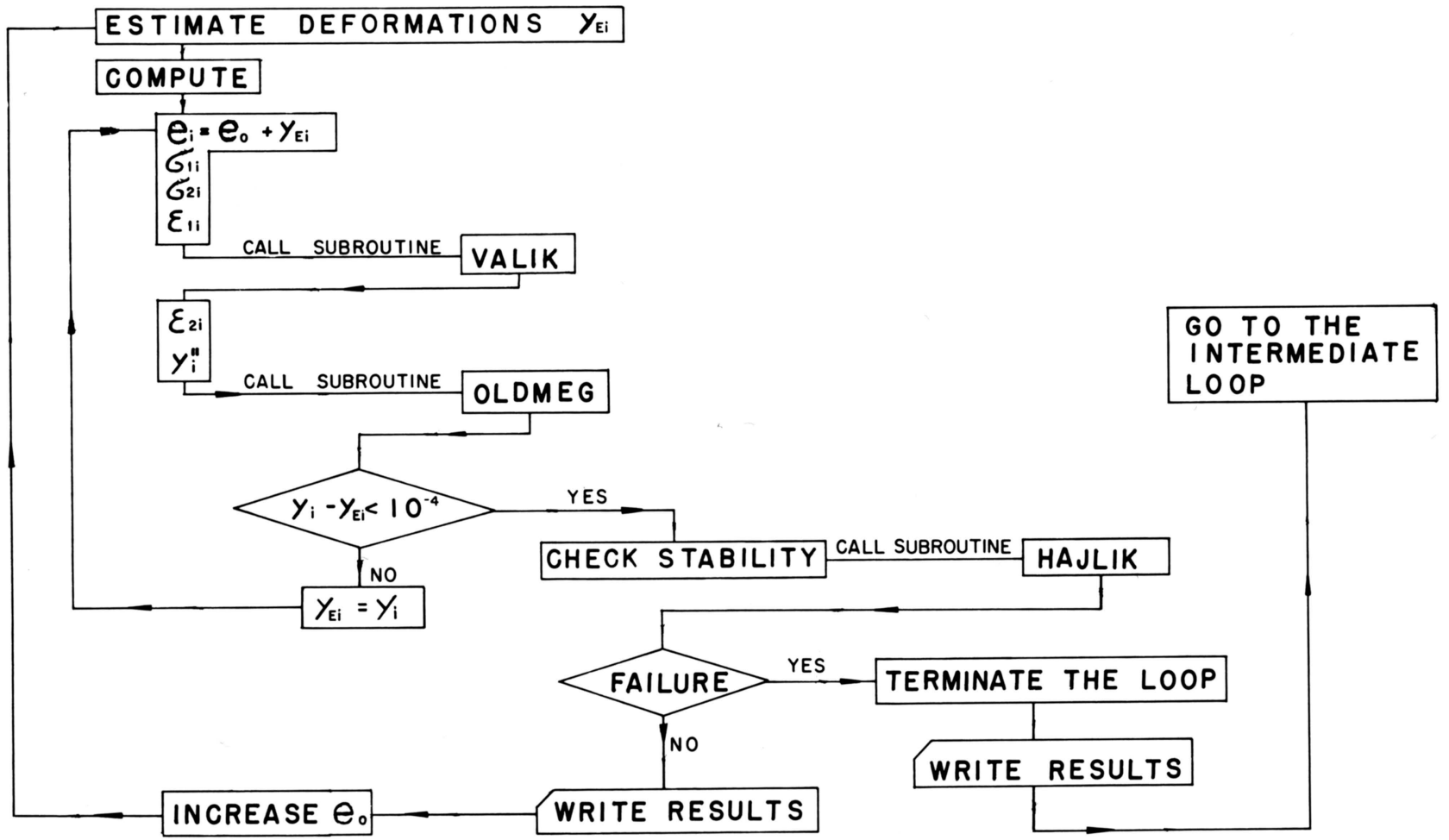


earlier than the limit state of stability, the former is registered and the execution of the inner loop is terminated. The intermediate and outer loops are executed in the same manner as the inner one.

\section{DISCUSSION OF THE RESULTS}

The operation, outlined in the previous section, resulted in a number of families of function, i.e., curves given numerically. These curves describe the relations between the corresponding stresses, strains, deformations, loads, and eccentricities that pertain to a selected cross-section of the column. Cross-sections were chosen at $1 / 2,3 / 8,1 / 4$, and $1 / 8$ of the length, and at the end of the column. The families can be grouped conveniently into two sets.

The first set, representing the first loading process for each column, describes relations between stresses and eccentricities for each value of the variable load parameter $P$. This set includes $n_{p}$ families of curves, where $n_{p}$ indicates the number of loads considered. Each family consists of five pairs of curves, one pair for each cross-section. Each pair consists of one curve for $\sigma_{1}$ and one for $\sigma_{2}$.

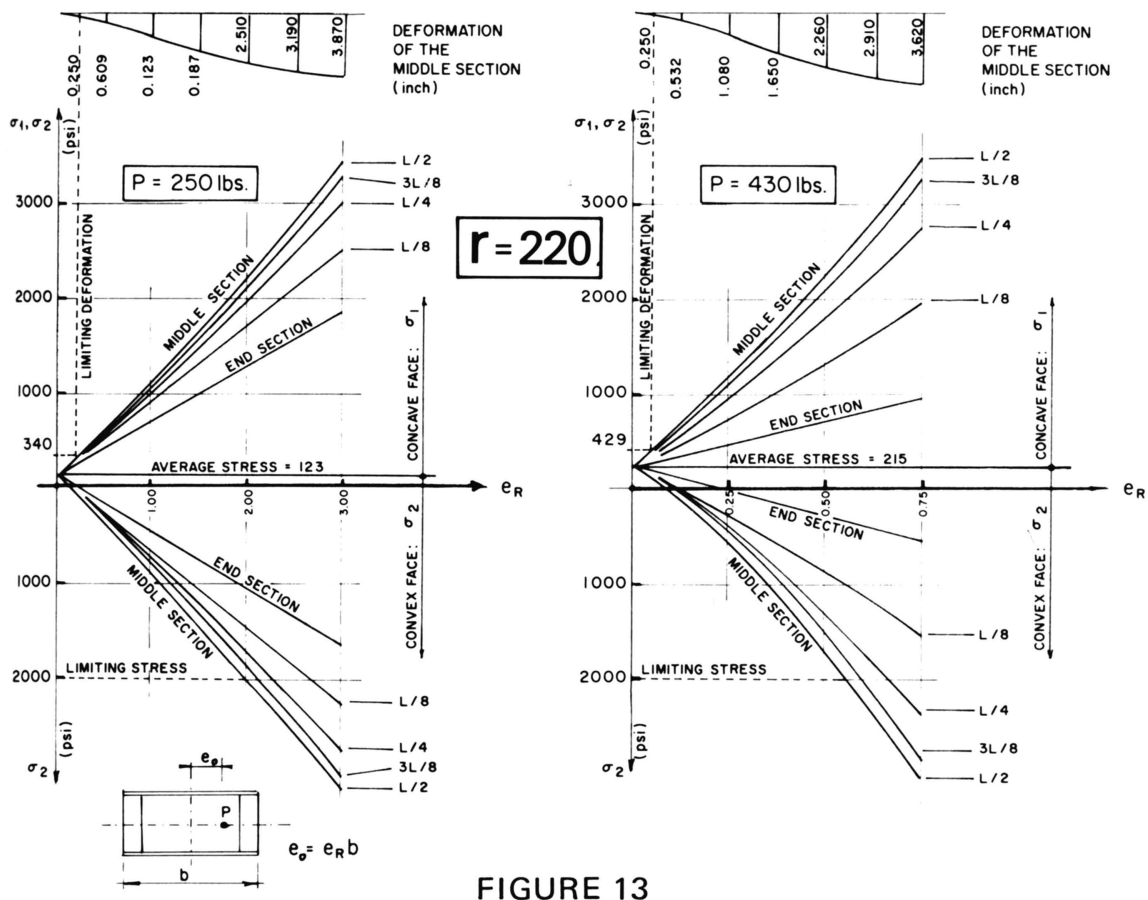

Representation of the 1st Loading Process for a Very Slender Column $r=\mathbf{2 0 0}$, and for Constant Loads:

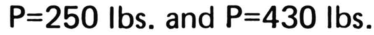



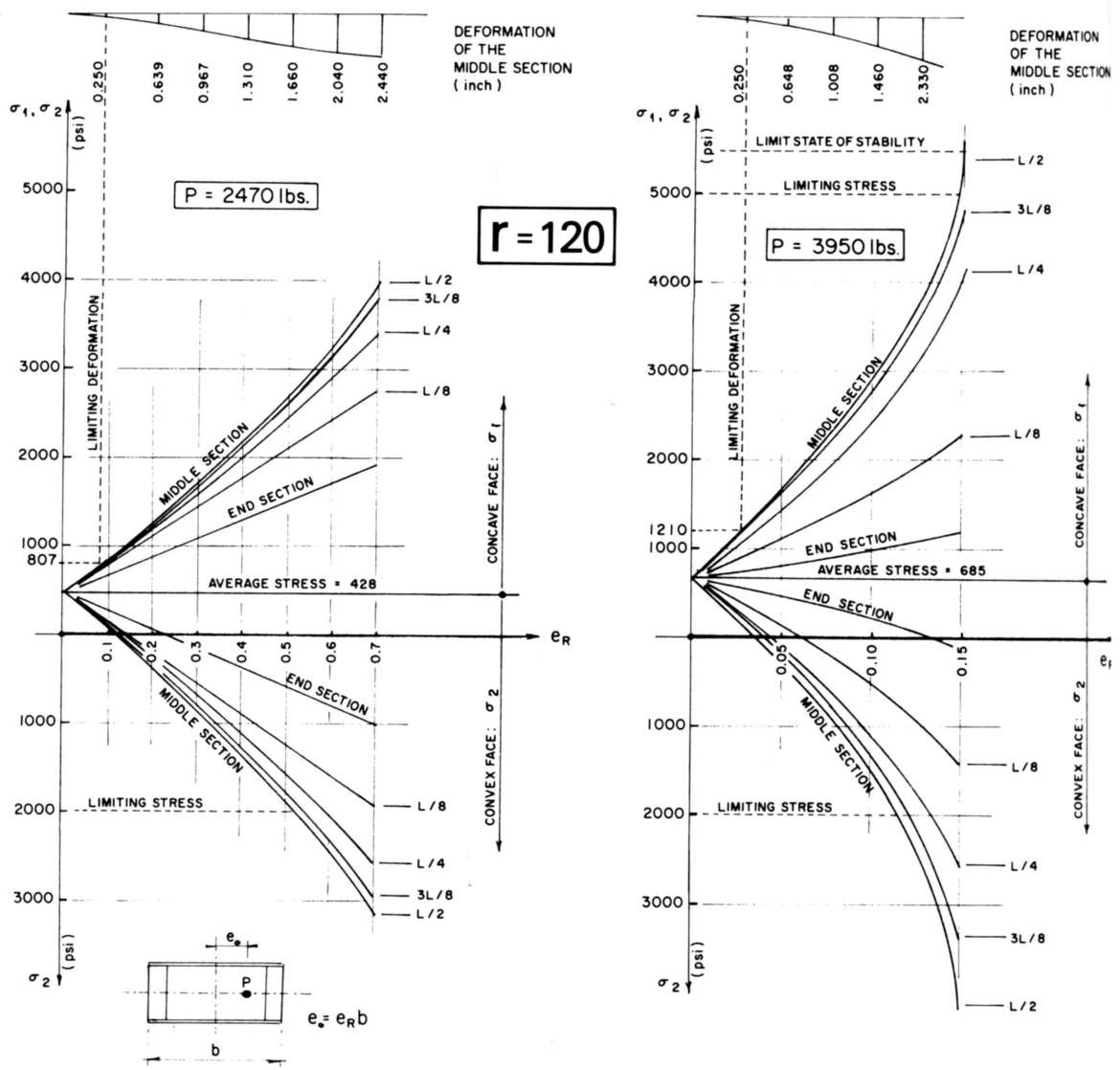

FIGURE 14

Representation of the 1st Loading Process for a Medium Column $r=120$, and for Constant Loads:

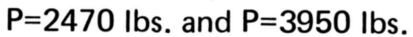

The second set, representing the second loading process for each column, describes the relations between stresses and loads in terms of the variable eccentricity parameter $e_{0}$. The set includes $n_{e}$ families of curves, where $n_{e}$ indicates the number of eccentricities considered. Each family again consists of five pairs of curves, and each pair is related to a particular cross-section of the column.

In order to compare columns of various slenderness ratios, the term relative eccentricity $e_{R}$ is introduced and is defined as the ratio of the initial eccentricity $e_{o}$ to the dimension $b$ of the cross-section of the columns; i.e.: $e_{o}=b_{R}$ 

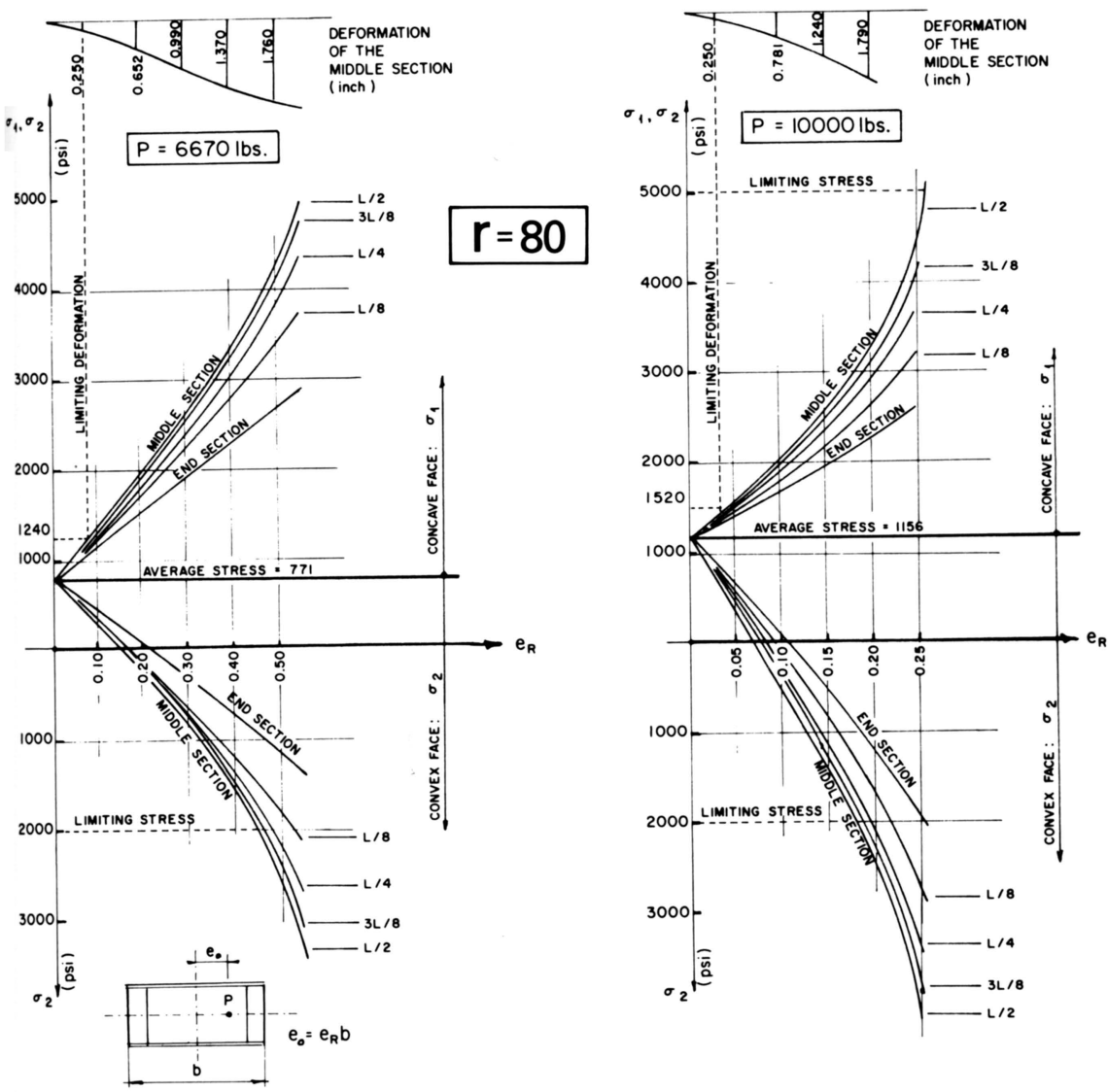

FIGURE 15

Representation of the 1st Loading Process for a Medium Column $\mathrm{r}=\mathbf{8 0}$, and for Constant Loads:

$P=6670 \mathrm{lbs}$. and $\mathrm{P}=10000 \mathrm{lbs}$.

\section{The First Loading Process}

Figs. 13-16 represent typical families of the first set, corresponding to high, medium and low values of the slenderness ratio, and under the first loading process. It can be seen that stresses along the concave face always increase, but that a definite stress decrease occurs along the convex face. At higher load levels, the vertex of the corresponding family of curves appears at a higher stress level( $\sigma_{\mathrm{ov}}$ increases), and the curves of the family become steeper. Nevertheless, the pattern of the family remains the same for all loads and for all slenderness ratios (i.e., $\sigma_{1}$ increases and $\sigma_{2}$ decreases), and the behavior of the column 


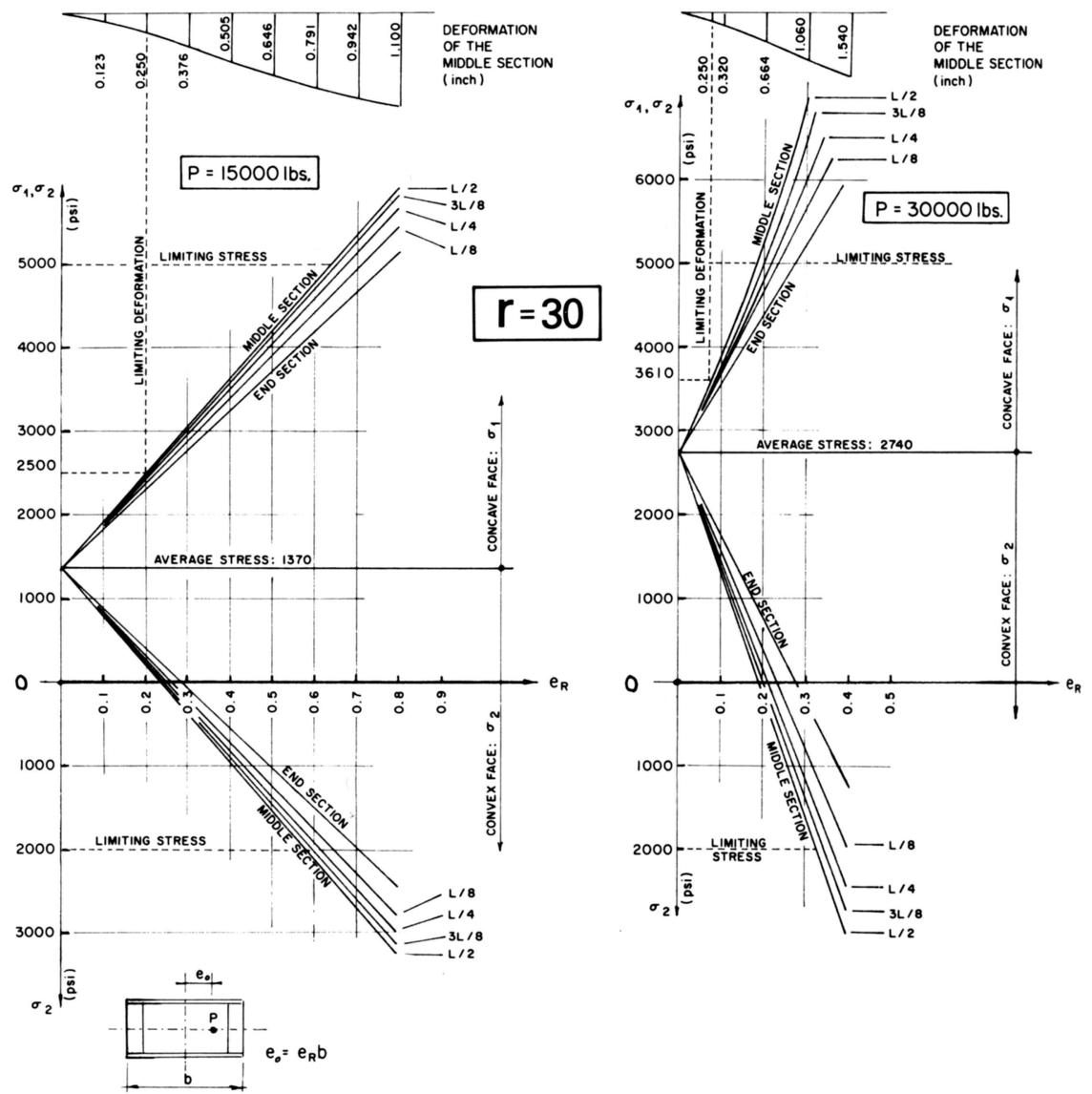

FIGURE 16

Representation of the 1st Loading Process for

a Short Column r $=30$, and for Constant Loads:

$P=15000 \mathrm{lbs}$. and $P=30000 \mathrm{lbs}$.

follows the stress-strain diagram shown in Fig. 7. The phenomenon associated with the loading process starts at $\sigma=\sigma_{\mathrm{ov}}$ as a point of bifurcation. Consequently, the behavior of the column during the first loading process is similar to the pattern imposed by Von Karman for centrically loaded columns.

It can also be seen that the first loading process will never lead to stability failure (Figs. 13-16). For slenderness ratios between 80 and 120, and for high loads. columns have a tendency to reach some theoretical limit state of stability (Fig. 14, 15). These limits, however, pertain to a stress level which is higher than the limit state of stresses. Consequently, stability failure is hypothetical, and 
during the first loading process the columns behave as beam columns (i.e., the bending moment is the predominant action and the axial force is inferior).

It must be pointed out, however, that this behavior of wooden columns is due to their low value of Young's modulus. For steel columns, and for slenderness ratios higher than 110 , stability failure can always be achieved at relatively low stress levels.

\section{The Second Loading Process}

Figs. 17-19 represent typical families under the second loading process. It can be observed that the phenomenon produced by this loading process starts at $\sigma=\sigma_{\mathrm{av}}=0$ as a point of bifurcation. However, a significant difference in the behavior of columns occurs if the eccentricity is less or greater than the kern radius.

Figs. 17A, 18A, and 19A represent typical families of the second set corresponding to high, medium, and low values of the slenderness ratio. The eccentricity for each family is less than the corresponding kern radius. These figures show that along the concave face of the columns definite stress increases occur. Along the convex face, however, the fiber stresses first increase and then decrease. Although the rate of change of the stresses is different in each cross-section, and for each family, the general behavior of the entire set shows a definite character, i.e., $\sigma_{2}$ first increases then decreases. It can be recognized that the behavior of the columns under this condition obeys the stress-strain diagram shown in Fig. 8. Consequently, the phenomenon is similar to that predicted by Shanley for centrically loaded columns.

Figs. 17B, 18B, and 19B represent other families of the second set. The eccentricities here are greater than the corresponding kern radii. It can be seen that the fiber stresses increase monotonously along the concave face and decrease monotonously along the convex faces. The stress-strain diagram that reflects this behavior can be obtained from that of Fig. 8 by shifting point $A$ to the origin. The behavior of columns that obey this kind of stress-strain diagram has not yet been discussed by others; thus an investigation in this area could extend the Shanley Theory for eccentrically loaded columns.

It can also be seen that the second loading process frequently leads to stability failure if the eccentricity is less than the kern radius. Columns under this process behave as real columns, i.e., the magnitude of the load is the predominant factor and the eccentricity is inferior. For these columns the limit state of stability is achieved at a lower stress level than the limit state of stresses; consequently, the limit state of stresses becomes a hypothetical value. If the 


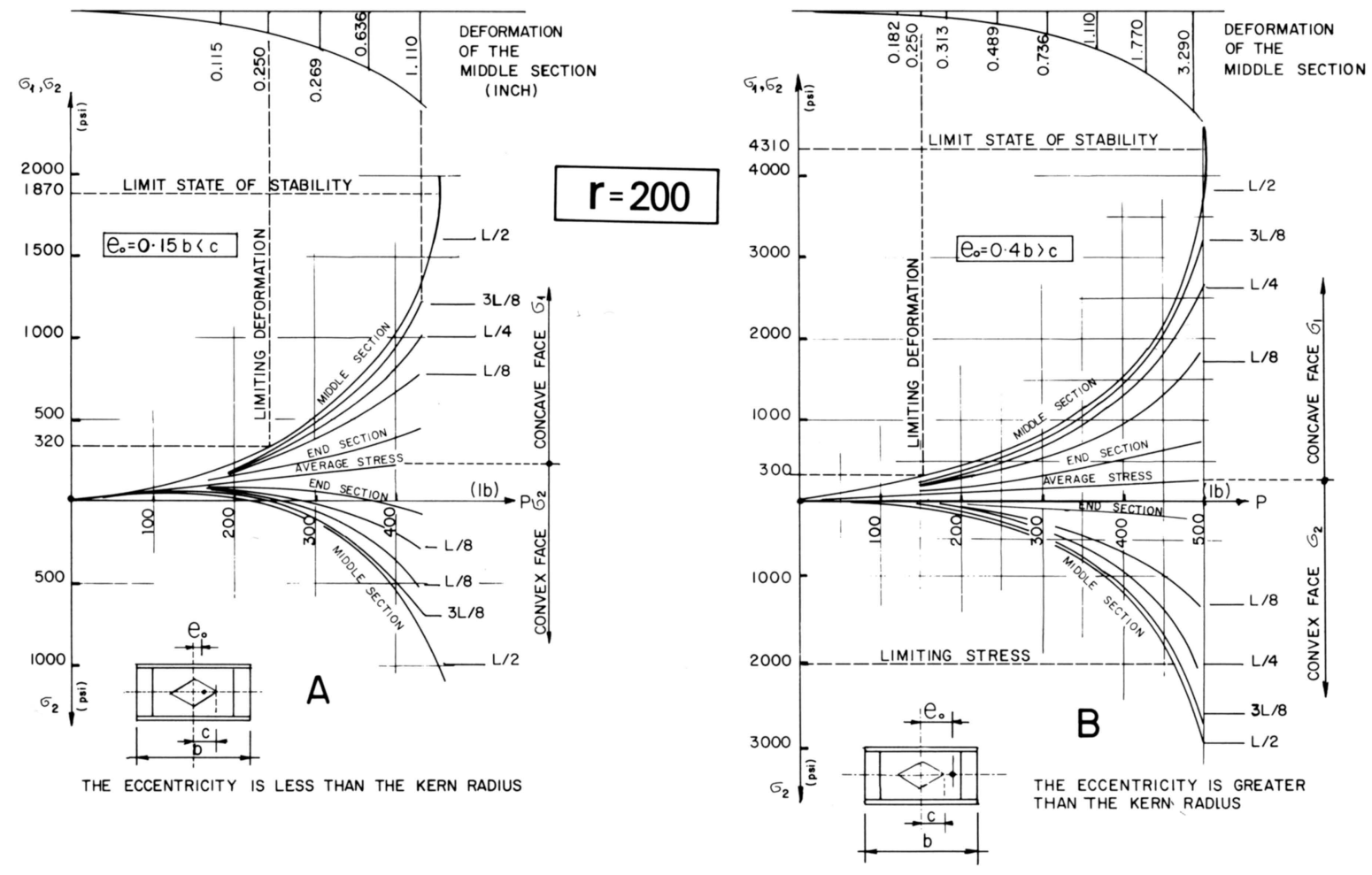

FIGURE 17

Representation of the 2nd Loading Process for a Very

Slender Column r=200 and for Two Different Eccentricities 


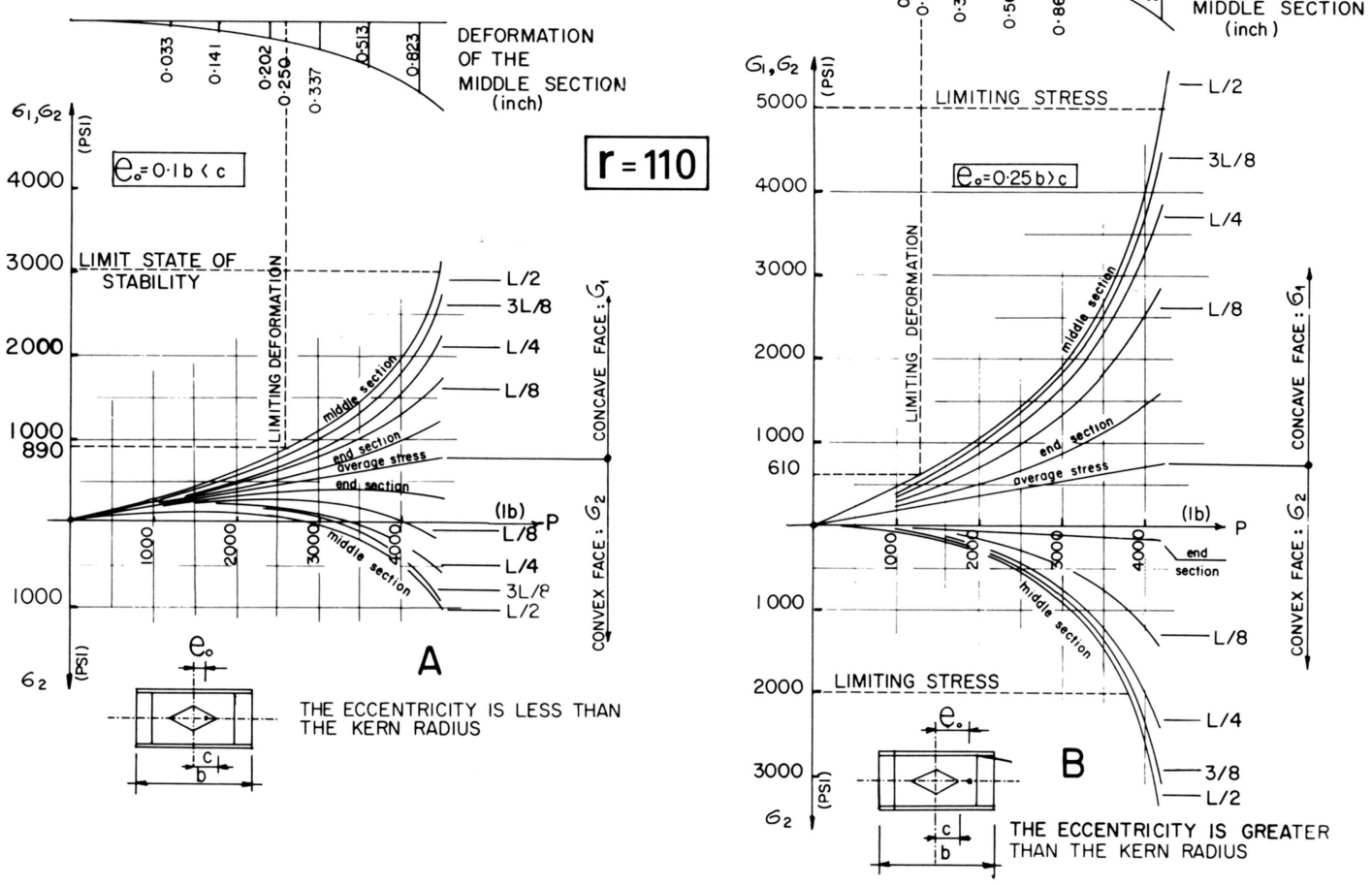

FIGURE 18

Representation of the 2nd Loading Process for a 


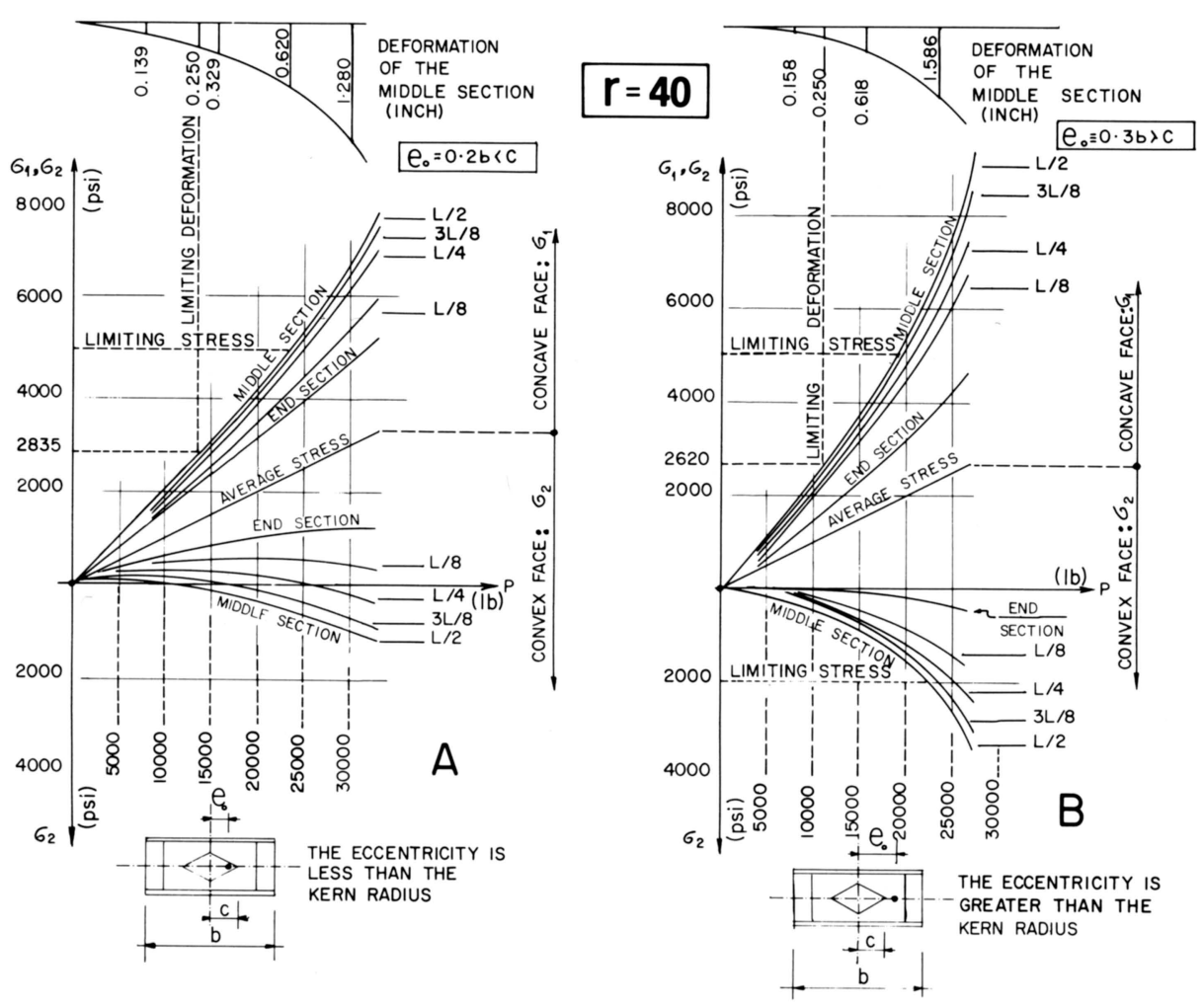

FIGURE 19

Representation of the 2nd Loading Process for a

Short Column $r=40$, and for Two Different Eccentricities 
eccentricity is greater than the kern radius, columns behave as beam-columns, except those of very high slenderness ratios (Fig. 17B).

\section{The Third Loading Process}

The third loading process includes a simultaneous increase of the load and the eccentricity, and is therefore a combination of the first and second loading processes. Fiber stresses increase in both concave and convex faces as long as the load is small and the eccentricity is less than the kern radius. If the eccentricity is greater than the kern radius, with increasing load, stress decreases occur along the convex face. The phenomenon obeys the stress-strain diagram of Fig. 8, and begins at $\sigma=\sigma_{\mathrm{av}}=0$ as a point of bifurcation. Consequently, the behavior of the column under this loading process follows the Shanley pattern or the Von Karman pattern, depending on whether the eccentricity is less or greater than the kern radius. Since all the steps of the process are included in the first and second ones, the third loading process is not of particular interest.

\section{LIMITATION OF THE DEFORMATIONS}

As a result of relatively low modulus of elasticity values, wood columns undergo fairly large deformations. Figs. 13-16 and Figs. 17-19 show that deformations, even for short columns and at stress levels equal to the limit state of stresses, are so extensive that they cannot be tolerated in practice. Consequently, some limitation of the deformation becomes inevitable. A limit state of deformation has been suggested, and was considered in this study to be equal to $1 / 400$ of the reduced column length. This corresponds to 0.25 inch deformation measured at the middle of the columns. It can be seen that effective stresses in the columns always are below both the limit state of stresses and the limit state of stability when the deformations do not exceed the above limitation. The situation is similar for $\mathrm{L} / 300$ and $\mathrm{L} / 250$ deformation limitations. The stress level ratios of the actual failure of the column (limit state of stresses or stability) to those levels observed at a deformation limit of L/400 vary between 2 and 4, depending on whether the slenderness ratio is low or high. Consequently, the load parameters $P$ and $e_{0}$ that pertain to the stress level of L/400 deformation include, in advance, a load factor of minimum 2 .

Based on this concept, nomograms were constructed for the relations between the magnitudes of the loads and their eccentricities, and these relations were represented for each of the selected slenderness ratios (Figs. 20, 21). Each point of a nomogram hyperbola defines a unique pair of load parameters with a load factor of minimum 2. It follows that the nomograms can be used to design eccentrically loaded columns, or to analyze the load bearing capacity of given columns at various eccentricities. 


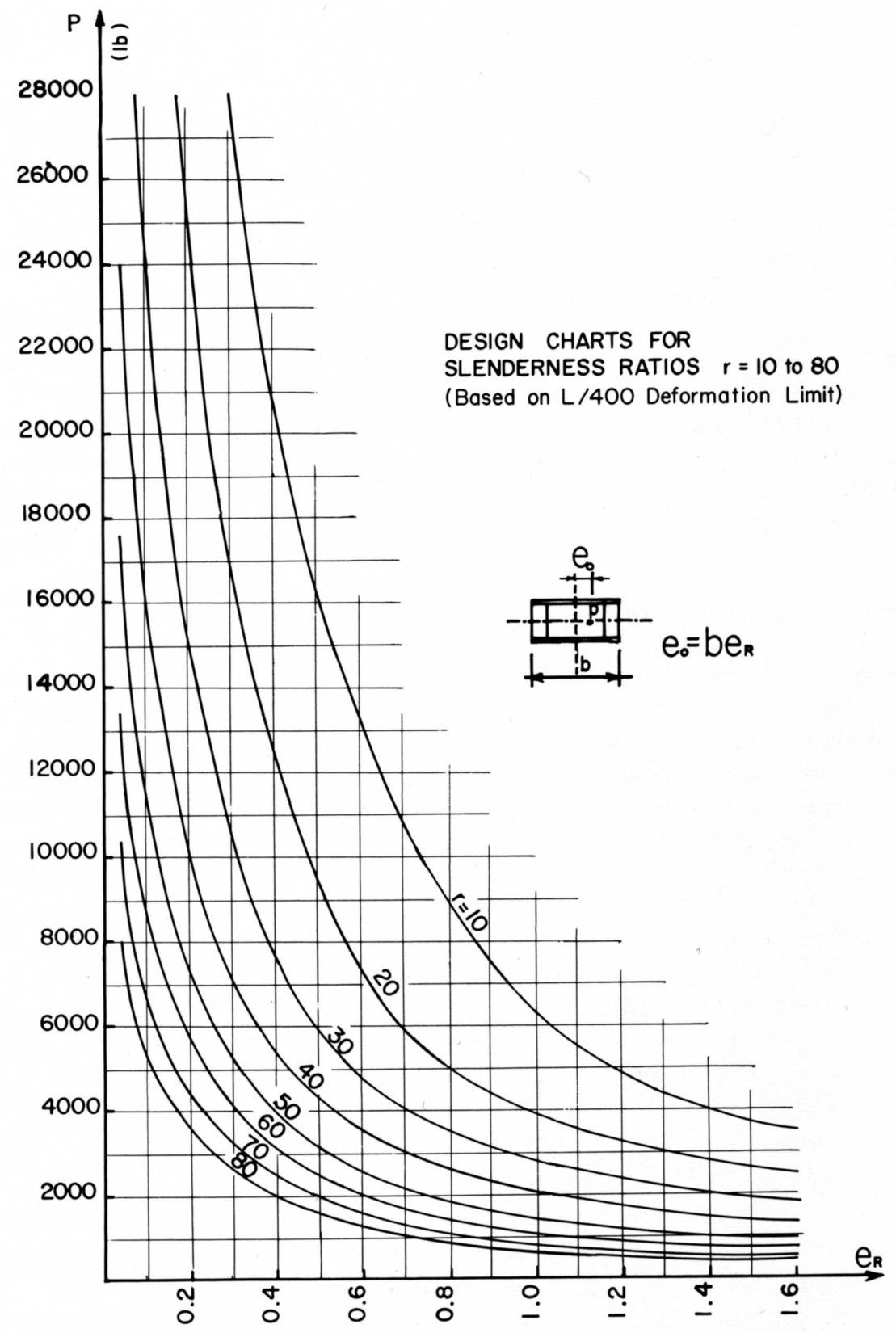

FIGURE 20 


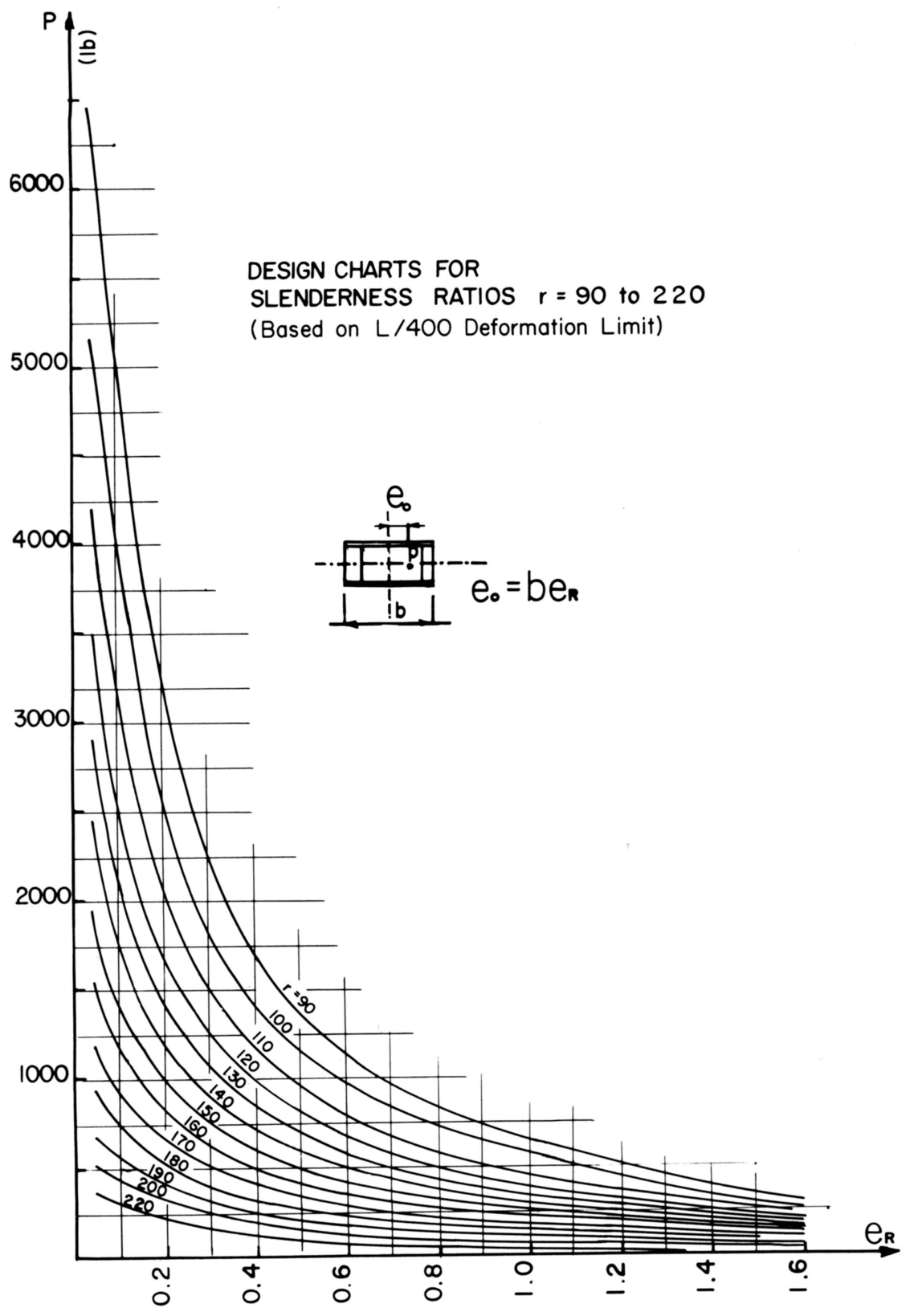

FIGURE 21 


\section{SUMMARY AND CONCLUSIONS}

A general analysis has been elaborated to determine the load-bearing capacity, the stress distribution, and the behavior of columns under eccentric loads, and a numerical method developed to solve a quasi linear problem for thin-walled box columns. The most important findings were:

1. Centrically loaded columns behave as described by the stress-strain diagram for the material.

2. Since centrically loaded columns do not exist in practice, realistic analysis should be based on the consideration of eccentric loads and, in case of wood, on an elasto-plastic stress-strain diagram. The general (hypothetical) solution for centrically loaded columns is obtained by analyzing columns with eccentric loads as eccentricity approaches zero.

3. The failure of eccentrically loaded columns may occur either at the limit state of stresses or at the onset of buckling. The latter was defined as a limit state of the column at which, for any infinitesimal increment in the load or in the eccentricity, the related change in the fiber stresses will have a finite value. This definition makes it possible to solve stability problems for eccentrically loaded columns in a similar manner as stress problems. With this definition, however, the stability problem is not an eigenvalue problem.

4. The behavior of eccentrically loaded columns is described best in terms of the loading process. Under the first loading process columns behave as beamcolumns and follow Von Karman's assumptions. The actual failure of a column occurs at the limit state of stresses. Under the second loading process, and for eccentricities less than the kern radius, columns behave as real columns and follow the Shanley pattern. Failure is generally stability failure, and occurs at a stress level lower than the limit state of stresses. If the eccentricity is greater than the kern radius, the behavior of the column is again similar to that of a beam-column but follows a new pattern not previously observed. Failure occurs at the limit state of stresses. Consequently, whether the limit state of stability is reached at a higher (hypothetical) or lower (real) stress level than the limit state of stresses depends on the loading process. This can be observed by comparing Figs. 13 and 17. These findings are of utmost importance in the analysis of columns near the onset of buckling or in the post-buckling region; nevertheless, the second order theory (equation 18) provides much more accurate information in these regions.

5. In the pre-buckling region, however, the load parameters $P$ and $e_{0}$ are limited by the limit state of deformation. This was assumed in the present study to be 
$1 / 400$ of the reduced column length, and thus corresponds to small deformations of the columns. Based on this limitation, design nomograms were developed to include a load factor of minimum 2.

Detailed treatment of the entire range of analytical and numerical solutions to problems encountered with eccentrically loaded columns is beyond the scope of this bulletin. The goal here has been to elaborate a minimal framework for the new approach and to suggest appropriate analytical and numerical techniques. Some special problems that will require attention are outlined below.

\section{SUGGESTIONS FOR FURTHER RESEARCH}

In this study it was tacitly assumed that relative displacements between the elements of the column (webs and flanges) do not take place. This is not true for nailed columns. For these, the joint slip should be expressed in terms of the strains, and introduced in (17). The governing differential equation will be of 4 th or 6 th order, and can be solved by a suitable numerical technique for various boundary conditions. If one accepts the L/400 deflection limitation (corresponding to small deformation of the column), the linearized theory (19) can be employed. The solution may be adopted as a subroutine in the general computer program.

Neither the Building Codes nor the National Design Specification includes specified allowable deformations for columns. Columns, on the other hand, do undergo deformation if the eccentricity satisfies equation 16 . Allowable column deformation was, therefore, assumed in this study to be 1/400 of the reduced column length. This value, even if acceptable, cannot be generalized. For example, different deflection limitations should be postualted for free, semidetached, or wall columns. This problem should be discussed by an appropriate committee.

The present study does not include the analysis for centrically loaded columns. Since centrically loaded columns form singular cases of the entire column problem, the reverse of the first loading process may lead to a solution for centrically loaded columns. A slight modification of the numerical method, and of the related computer program, should provide the desired result. 


\section{BIBLIOGRAPHY}

1. Euler L.: De Curvis Elasticis.

Lausanne - Genève, 1744.

2. Engesser F.:

Die Sicherung offener Brücken gegen Ausknicken.

Zentrbl. der Bauverwalt, 1884.

3. Considère $A$ : $\quad$ Congres International des Procedes de Construction.

Paris, 1889.

4. Von Karman TH.: Untersuchungen über Knickfestigkeit. Mitteilungen über Forschungen auf dem Gebiete des Ing. -Wesens.

Heft 81. Berlin, 1910.

5. Shanley F. R.: Inelastic Column Theory. Journ. of the Aeronat. Soc. Vol. 14, 1947.

6. Shanley F. R.: The Column Paradox. Journ. of the Aeronat. Soc. 1964.

7. Müller-Breslau H.: Über Exzentrisch gedruckte Stäbe und über Knickfestigkeit. Eisenbau, 1911.

8. Dutheil J.: Le Flambement des Eléments Comprimees dans les Ossatures en Acier. Inst. Techn. Bat. Trav. Pub. Circ. Série I. No. 35, 1957. 